ARTICLE

DOI: $10.1038 / s 41467-018-06316-9$

\title{
Eosinophil recruitment is dynamically regulated by interplay among lung dendritic cell subsets after allergen challenge
}

Shuying $\mathrm{Yi}^{1}{ }^{1,2}$, Jing Zhai ${ }^{2}$, Rui Niu${ }^{1}$, Guangming Zhu' ${ }^{1}$, Meixiang Wang ${ }^{3}$, Jianguo Liu ${ }^{1}$, Hua Huang ${ }^{1}$, Yaping Wang ${ }^{1}$, Xiuli Jing ${ }^{1}$, Li Kang ${ }^{1,2}$, Wengang Song ${ }^{1,2}$, Yufang Shi (i) ${ }^{4}$ \& Hua Tang ${ }^{1,3}$

Eosinophil infiltration, a hallmark of allergic asthma, is essential for type 2 immune responses. How the initial eosinophil recruitment is regulated by lung dendritic cell (DC) subsets during the memory stage after allergen challenge is unclear. Here, we show that the initial eosinophil infiltration is dependent on lung $C D C 1 s$, which require nitric oxide $(N O)$ produced by inducible NO synthase from lung $\mathrm{CD} 24^{-} \mathrm{CD} 11 b^{+} \mathrm{DC} 2 \mathrm{~s}$ for inducing CCL17 and CCL22 to attract eosinophils. During late phase responses after allergen challenge, lung $C D 24^{+} \mathrm{CDC} 2 \mathrm{~s}$ inhibit eosinophil recruitment through secretion of TGF- $\beta 1$, which impairs the expression of CCL17 and CCL22. Our data suggest that different lung antigen-presenting cells modulate lung CDC1-mediated eosinophil recruitment dynamically, through secreting distinct soluble factors during the memory stage of chronic asthma after allergen challenge in the mouse.

\footnotetext{
${ }^{1}$ Institute of Immunology, Taishan Medical University, Taian 271000 Shandong, China. ${ }^{2}$ School of Basic Medical Sciences, Taishan Medical University, Taian 271000 Shandong, China. ${ }^{3}$ Shanghai Public Health Clinical Center, Fudan University, Shanghai 201508, China. ${ }^{4}$ Institute of Health Sciences, Shanghai Institutes for Biological Sciences, Shanghai 200031, China. Correspondence and requests for materials should be addressed to H.T. (email: tanghuazhang218@163.com)
} 
A llergic inflammatory asthma is a common disease that affects people worldwide ${ }^{1,2}$. It is mediated by several varieties of immune cells. Infiltration of eosinophils into the lung from the bone marrow and blood is the hallmark of eosinophilic allergic asthma ${ }^{1,3,4}$. Eosinophils are primarily considered terminally differentiated effector cells, but emerging data supports that eosinophils play a causal role in the augmentation of broader inflammation ${ }^{1,4-8}$. Targeting therapeutics to eosinophils has proved successful in controlling asthma in clinical trials $1,2,4,9-11$.

Eosinophil regulated by several cells, cytokines, and chemokines. IL-5 is essential for the expansion and mobilization of eosinophils from the bone marrow into the lung following allergen exposure ${ }^{3,12}$. CCL11 (eotaxin-1) and CCL24 (eotaxin-2) are the main chemokines involved in eosinophil recruitment ${ }^{3,12}$. Type 2 innate lymphoid cells (ILC2s) have been suggested to be potent inducers of eosinophil migration, either through their production of IL-5 or potentially through the production of CCL11 1,13-15. Upon allergen challenge, Th2 lymphocytes may produce large amounts of IL-5 $5^{11,16}$. However, other influencers of eosinophil accumulation in the lung are not yet fully elucidated.

Numerous studies have highlighted the involvement of dendritic cells (DCs) in the development of eosinophilic airway inflammation and asthma ${ }^{1,5,17} \cdot \mathrm{CD} 103^{+} \mathrm{cDC} 1 \mathrm{~s}$ and $\mathrm{CD} 11 \mathrm{~b}^{+}$ cDC2s are two major lung $\mathrm{CD} 11 \mathrm{c}^{+}$DC subsets. The division of labor among lung DC subsets is increasingly being recognized, with each subset showing both specific and overlapping functions ${ }^{18-20}$.

cDC1s have been shown to be involved in polarization toward Th1 and inhibition of Th2 responses via constitutive expression of IL-12 21,22 . A role for lung CDC1s in promoting Th2 response to inhaled allergens has also been demonstrated ${ }^{23,24}$, although contrary evidence has emerged from recent studies suggesting that $\mathrm{cDC} 1 \mathrm{~s}$ are not required for eosinophil infiltration during the primary immune response ${ }^{25,26}$. It remains necessary to determine whether lung $\mathrm{cDCl}$ s are or are not essential for eosinophil recruitment after allergen challenge.

cDC2s have been shown to be the dominant DC subset involved in promoting eosinophil infiltration during the primary immune response in acute allergic asthma ${ }^{25,27-30}$. However, whether and how cDC2s were involved in regulating eosinophil infiltration during immunological memory phase in chronic allergic asthma is still unclear. Furthermore, the necessity of professional APCs, including DCs, during the memory stage in chronic eosinophilic asthma ${ }^{31,32}$ has been challenged by a published study in which memory Th2 cells were responsible for IL33-mediated exacerbations of eosinophilic inflammation in a MHC II-independent manner ${ }^{33}$.

In our current study, we show that in a chronic allergic asthma mouse model focused on the memory stage after allergen challenge, the initial eosinophil recruitment is mediated by $\mathrm{cDC} 1 \mathrm{~s}$, which directly attract eosinophils by secreting CCL17 and CCL22. Furthermore, our data support the notion that $\mathrm{cDC1}$-mediated eosinophil infiltration is dynamically modulated by other lung DC subsets. On day 1.5 after the first allergen challenge, lung $\mathrm{CD} 24^{-} \mathrm{CD} 11 \mathrm{~b}^{+} \mathrm{DC} 2 \mathrm{~s}$ promote eosinophil infiltration via producing nitric oxide (NO), whereas $\mathrm{CD} 24^{+}$cDC2s inhibit this process by releasing TGF- $\beta 1$ on day 2.5 .

\section{Results}

Lung CD11 ${ }^{+}$DCs are required for eosinophil recruitment. To investigate eosinophil recruitment in the lung during memory stage after allergen challenge in a chronic mice model, we employed a kinetics analysis. Mice were sensitized with ovalbumin (OVA)/aluminum hydroxide (alum) by intraperitoneal (i.p.) injection and 28 days later challenged intranasally (i.n.) with OVA aerosol as the times indicated in Fig. 1a. Eosinophil infiltration in the lung and bronchoalveolar lavage fluid (Balf) were assayed at indicated time points by fluorescence-activated cell sorting (FACS). In the lung and Balf, eosinophils started to accumulate as early as 1.5 days after the first OVA challenge (Fig. 1a-c). This result was consistent with the previous work ${ }^{34}$.

It has been suggested that the initial eosinophil recruitment is required for the induction of a type 2 immune response to OVA aerosol challenge 8,35 . This was also confirmed by our data (Supplementary Fig. 1). However, how this early eosinophil infiltration is initiated has been largely unknown. We hypothesized that during the early eosinophil infiltration phase of OVA challenge, some lung cells may secrete certain chemokines to recruit eosinophils. To determine which cell type in the lung is capable to recruit eosinophils, we did an air-pouch assay as described $^{36,37}$. On day 1.5 after the first inhaled OVA challenge, $\mathrm{CD} 45^{+}$or $\mathrm{CD} 45^{-}$cells sorted from lungs were injected into mouse air pouches that had been prepared in advance in naive recipients. Twelve hours later, eosinophils in the air pouches were assayed by FACS (Fig. 1d, Supplementary Fig. 2). The results showed that lung $\mathrm{CD} 45^{+}$cells, but not CD45- cells, from OVAchallenged mice exhibited activity to recruit eosinophils (Fig. 1e). The results were also confirmed by transwell assay (Supplementary Fig. 3), suggesting that $\mathrm{CD} 45^{+}$hematopoietic cells recruit eosinophil directly.

Then we sought to determine among $\mathrm{CD} 45^{+}$cells which cell type could recruit eosinophils. Both $\mathrm{CD} 4^{+} \mathrm{T}$ cells and ILC2s have been proposed to play important roles in regulating eosinophil recruitment ${ }^{11,13,15}$. Memory Th2 cells are known to promote eosinophil infiltration through MHC II-independent paths ${ }^{33}$, which was confirmed by our results (Supplementary Fig. 4a, b). Ablation of $\mathrm{CD}^{+} \mathrm{T}$ cells resulted in significantly reduced eosinophil infiltration (Supplementary Fig. $4 \mathrm{c}-\mathrm{e}$ ), as reported in a previous study ${ }^{33}$. However, in the air-pouch assay, no eosinophil chemotactic effect was displayed by lung $\mathrm{CD} 4^{+} \mathrm{T}$ cells from mice on day 1.5 after the first OVA challenge (Fig. 1e), although the effect was displayed on day 2.5 after challenge (Fig. 1e). We also failed to observe lung ILC2s display any eosinophil recruitment competency both on day 1.5 and day 2.5 after challenge (Fig. 1e). These data collectively demonstrated that neither $\mathrm{CD} 4^{+} \mathrm{T}$ cells nor ILC2s were capable to recruit eosinophils by themselves on day 1.5 after the first challenge during the memory stage.

Given that the localization of DCs and alveolar macrophages (AMs) were closely associated with the airway and alveoli ${ }^{38,39}$, we hypothesized that DCs or AMs might be required to recruit eosinophils from blood vessels to the inflamed lung and alveoli. To test this, CD11c-DTR mice were used, as both DCs and AMs express CD11c. Intratracheal (i.t.) injection of diphtheria toxin (DT) into CD11c-DTR mice resulted in efficient depletion of DCs and AMs from the lung (Supplementary Fig. 5 and Fig. 1f, g). Data showed that the number of eosinophils in Balf and lung was significantly reduced in CD11c-DTR mice compared with wildtype mice (Fig. 1h). Consistent with previous data ${ }^{31,32}$, our results demonstrated that lung $\mathrm{CD}_{11 \mathrm{c}^{+}}$APCs are required for the recruitment of eosinophils in response to inhaled OVA challenge.

To further examine which CD11c ${ }^{+}$APCs subset was involved in eosinophil infiltration, we employed a mouse model in which AMs could be almost completely ablated within $24 \mathrm{~h}$ after clodronate liposome (CLL) i.t. injection and leave the lung CD11 ${ }^{+}$DCs intact (Fig. 1i, j), as has been described before ${ }^{40}$. We found that there was no noticeable change in the eosinophil infiltration in AM-ablated mice on day 1.5 after the first OVA challenge (Fig. 1k). These data demonstrated that OVA challenge-induced eosinophil infiltration was independent of AMs. This suggested that $\mathrm{CD}_{11 c^{+}} \mathrm{DCs}$ were critical for 
eosinophil recruitment. We also found that the temporal change curve of CD11c ${ }^{+}$DCs was similar to that of eosinophils both in the lung and Balf (Supplementary Fig. 6). We therefore sought to determine whether $\mathrm{CD}_{11 \mathrm{c}^{+}} \mathrm{DCs}$ are capable of inciting eosinophil infiltration in vivo. To test this, lung $\mathrm{CD}_{11 \mathrm{c}^{+}} \mathrm{DCs}$ and AMs were sorted on day 1.5 after the first OVA aerosol challenge and injected into the air pouches. Then, $12 \mathrm{~h}$ later, we calculated eosinophils in the air pouches with FACS and found that it was CD11 $\mathrm{c}^{+}$DCs, but not AMs, that attracted eosinophils in vivo (Fig. 11). These data strongly suggested that lung CD11 $\mathrm{c}^{+}$ a
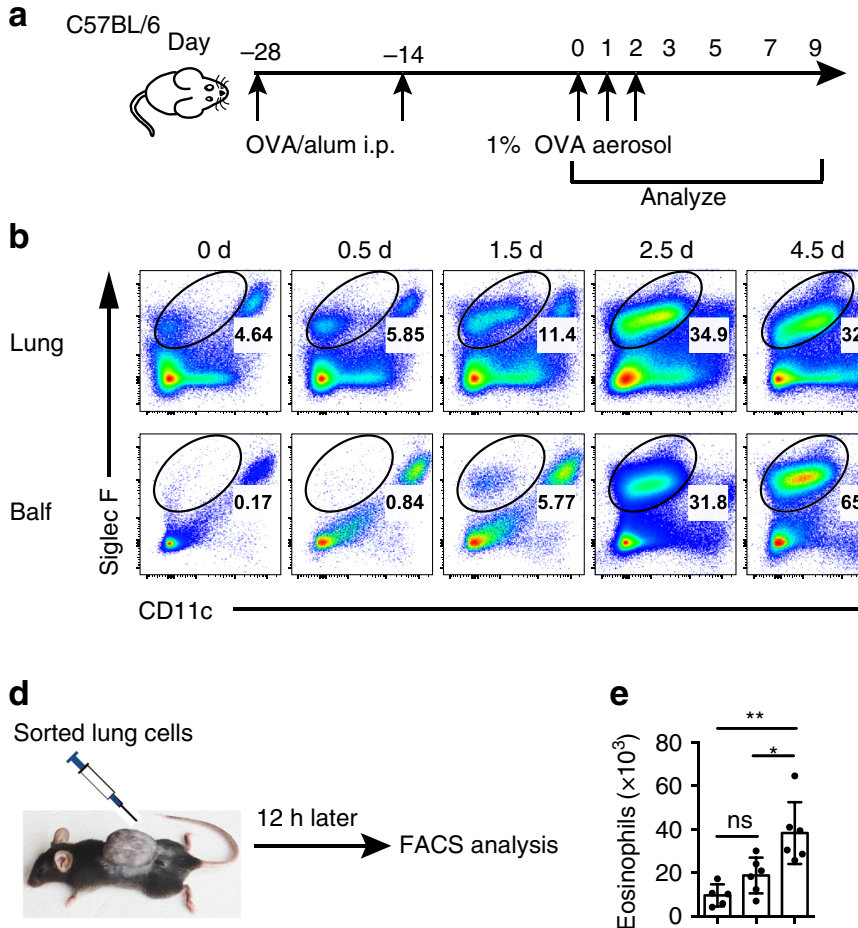

f

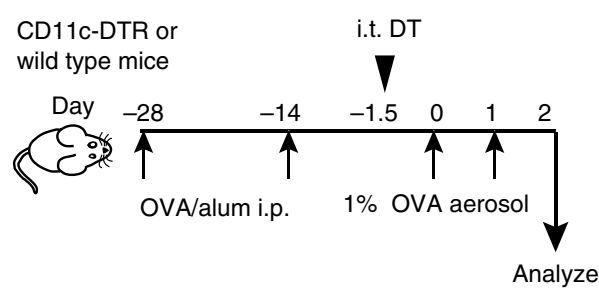

i C57BL/6

i.t. CLL or control

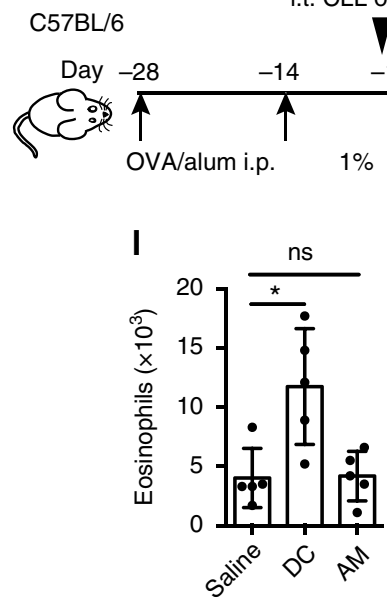

e

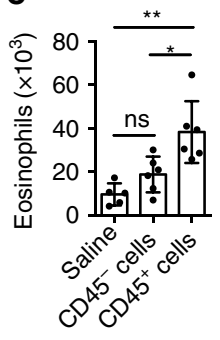

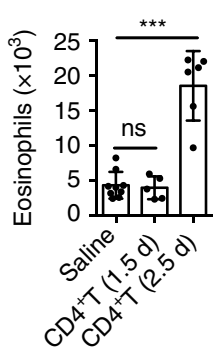
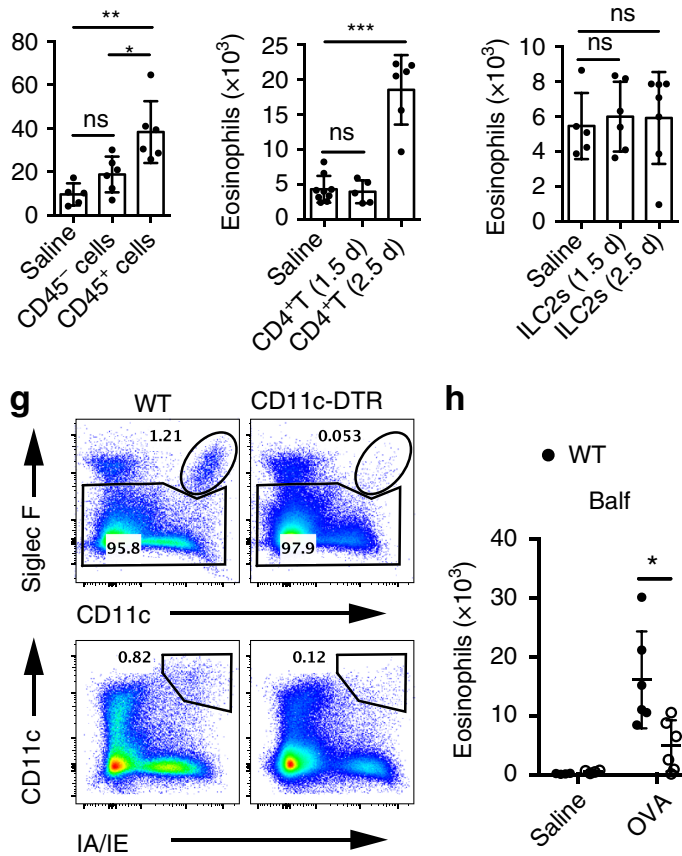

h
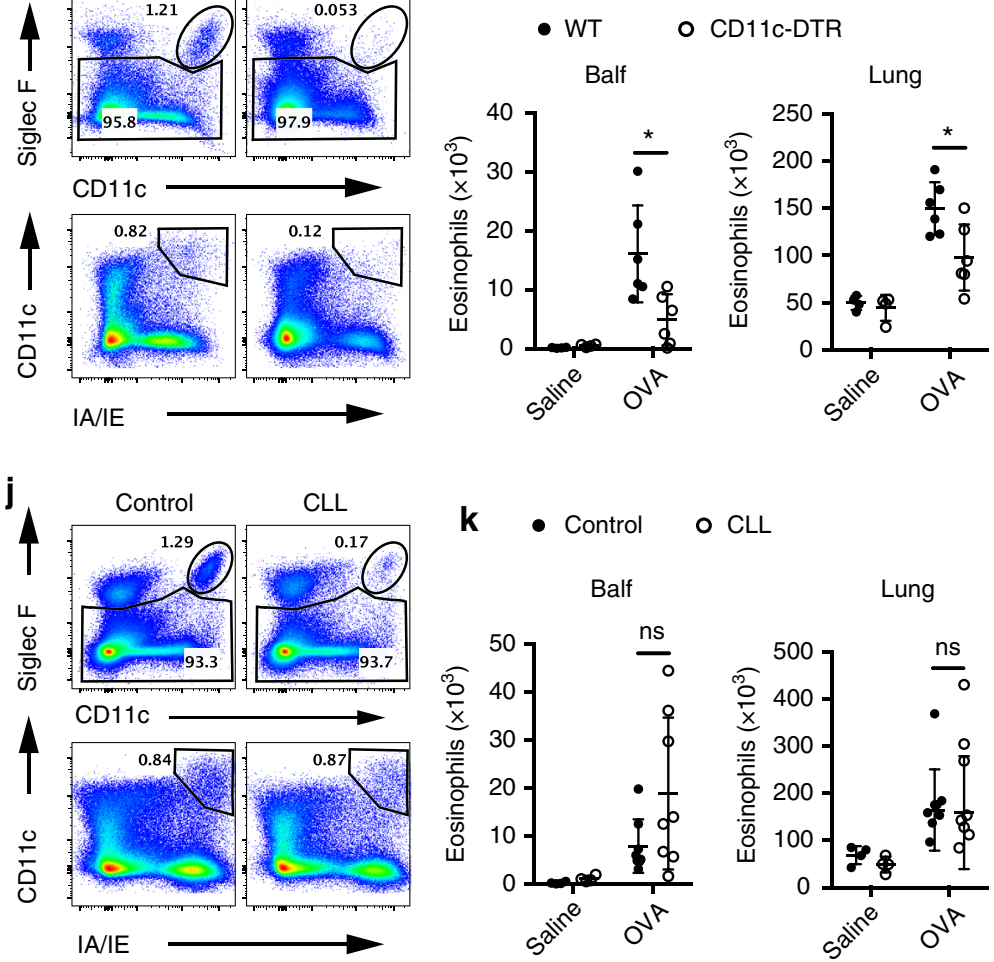

k
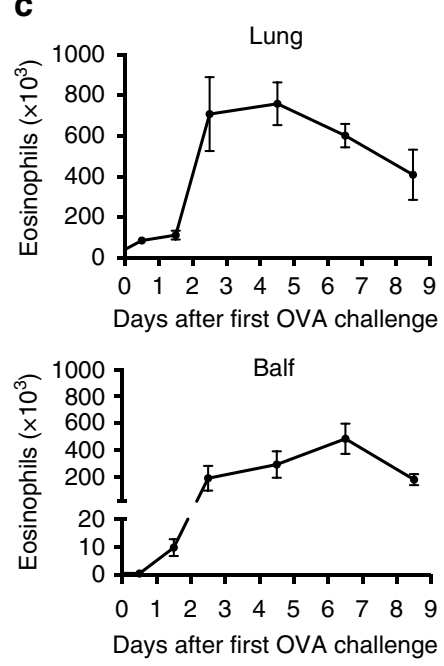

Days after first OVA challenge 
DCs were essential for the initial eosinophil accumulation during memory stage in chronic asthmatic inflammation after challenge, by recruiting eosinophils directly.

Lung cDC1s attract eosinophils at early infiltration phase. There are two major CD11c ${ }^{+}$DC subsets in the lung, $\mathrm{CD}_{103^{+}}$ DCs (cDC1s) and CD11b ${ }^{+}$DCs. $\mathrm{cDC} 1 \mathrm{~s}$ are more closely associated with the airway epithelium than are $\mathrm{CD} 11 \mathrm{~b}^{+} \mathrm{DCs}^{38}$. So we speculated that $\mathrm{CDC} 1 \mathrm{~s}$ may be more likely to be involved in recruiting eosinophils to the airway if they secrete a certain eosinophil chemotactic factor. To test this hypothesis, we first investigated whether lung $\mathrm{cDC} 1 \mathrm{~s}$ were required for the initial eosinophil infiltration during memory phase after inhaled allergen challenge. Therefore, we carried out experiments in Batf3 $3^{-1-}$ mice, in which $\mathrm{cDC} 1 \mathrm{~s}$ were selectively ablated due to severe defects in the development of this population ${ }^{41}$, as indicated in Fig. 2a. We found that after OVA aerosol challenge, the eosinophil infiltration in the Balf and lung from Batf3-l- mice was significantly decreased compared with wild type mice, suggesting that $\mathrm{cDCl}$ s are required for the initial eosinophil accumulation (Fig. 2b). To confirm that these results were not specific to the OVA model, we performed experiments in a different established mouse model of asthma, in which inhaled cysteine protease papain was used as an allergen (Fig. 2c). As shown in Fig. 2d, similarly, during memory stage after papain challenge, the eosinophil infiltration in the Balf and lung from Batf3 $3^{-}$mice was significantly reduced. To ablate $\mathrm{cDCls}$ immediately before the challenge, langerin-DTR mice were used, as CDC1s express langerin. Lung $\mathrm{CDC} 1 \mathrm{~s}$ could be selectively depleted in langerin-DTR mice within $24 \mathrm{~h}$ of the injection of DT (Fig. 2e, Supplementary Fig. 7). Mice were challenged 1 day after DT treatment with OVA aerosol. We found that treatment with DT resulted in significantly decreased eosinophil numbers both in the lungs and in Balf (Fig. 2f). Similarly, depletion of lung $\mathrm{cDC} 1 \mathrm{~s}$ in langerin-DTR mice with DT also impaired eosinophil infiltration induced by papain challenge in a papain sensitization/challenge-induced asthma model (Fig. 2g). Collectively, these experiments demonstrated that during the memory stage of chronic asthma, allergen challenge-induced eosinophil infiltration was dependent on lung cDC1s.

To determine whether lung cDC1s from inhaled allergenchallenged mice were capable of recruiting eosinophils in vivo, we sorted lung $\mathrm{cDC} 1 \mathrm{~s}$ and $\mathrm{CD} 11 \mathrm{~b}^{+}$DCs by FACS from mice on day 1.5 after first OVA aerosol challenge, and then injected them into air pouches. Although both lung $\mathrm{cDC} 1 \mathrm{~s}$ and $\mathrm{CD}_{11} \mathrm{~b}^{+} \mathrm{DCs}$ displayed the capacity to recruit eosinophils, $\mathrm{cDC1}$ s were much more efficient than $\mathrm{CD} 1 \mathrm{~b}^{+}$DCs at recruiting eosinophils (Fig. 2h). To examine whether lung $\mathrm{cDC} 1$ s from mice challenged with papain were also capable to recruit eosinophils, we performed the similar air pouch experiments. As expected, lung
cDC1s from papain challenged mice could recruit eosinophils, although $\mathrm{CD}_{11 \mathrm{~b}^{+}}$DCs displayed similar capacity (Fig. 2i). As lung monocyte-derived cells (MCs) and lung interstitial macrophages (IMs) may also express MHC II and low to intermediate levels of CD11c, it is possible that the lower capacity of CD11b DCs to attract eosinophils in the air pouch assay was caused by MC or IM contamination. We adopted a recent strategy with a few modifications to identify these different $\mathrm{CD} 11 \mathrm{~b}^{+}$cells and exclude MCs and IMs from CD $11 b^{+}$DCs (Supplementary Fig. 8) ${ }^{42}$. Also, recently, it has been suggested that lung $\mathrm{CD}_{11} \mathrm{~b}^{+}$DCs can be further divided into $\mathrm{CD} 24^{+} \mathrm{cDC} 2 \mathrm{~s}$ and $\mathrm{CD} 24^{-}$DCs based on CD24 expression ${ }^{27}$. We also tried to divide $\mathrm{CD}_{11 \mathrm{~b}}{ }^{+} \mathrm{DCs}$ into $\mathrm{CD}_{24}{ }^{+}$and $\mathrm{CD} 24^{-}$populations. However, considering that the CD24- population has not been genetically demonstrated as a bona fide flt3l-dependent and maybe IRF4 independent subset ${ }^{43}$, we used $\mathrm{CD} 24^{-} \mathrm{CD} 11 \mathrm{~b}^{+} \mathrm{DC} 2 \mathrm{~s}$ to name this population hereafter, although they are phenotypically CD64- F4/80- Mertk ${ }^{-} \mathrm{CD}_{11 \mathrm{c}^{+} \mathrm{MHCII}^{+} \mathrm{CD} 26^{+}{ }^{+} \text {Sirpa }}{ }^{+}$and originally CCR2 independent (Supplementary Fig. 9). Considering that the temporal changes of DC subsets (CD24+ ${ }^{+} \mathrm{CDC} 2 \mathrm{~s}$ and $\mathrm{CD} 24^{-} \mathrm{CD} 11 \mathrm{~b}^{+}$ DC2s) in the lung were associated with the kinetic change of eosinophil (Supplementary Fig. 10), we sought to test which $\mathrm{CD} 11 \mathrm{~b}^{+}$cell subset $\left(\mathrm{MCs}, \mathrm{IMs}, \mathrm{CD} 24^{+} \mathrm{cDC} 2 \mathrm{~s}\right.$, or CD24-CD11b $+\mathrm{DC} 2 \mathrm{~s})$ is more efficient in recruiting eosinophils in the air pouch assay. Our results showed that lung CD $24^{+} \mathrm{cDC} 2 \mathrm{~s}$ and MCs could recruit eosinophils, but were less efficient than $\mathrm{cDC} 1 \mathrm{~s}$ (Fig. 2j). We failed to find any chemotactic effects of lung CD24 ${ }^{-}$CD $11 b^{+}$DC2s and IMs (Fig. 2j).

To examine whether cDC1s attract eosinophils directly, transwell assays were performed. As shown in Fig. $2 \mathrm{k}, \mathrm{cDC} 1 \mathrm{~s}$ indeed recruited eosinophils directly in vitro and were more efficient than other $\mathrm{CD} 11 \mathrm{~b}^{+}$cell subsets. To determine whether lung $\mathrm{CDC} 1$ s from OVA-challenged mice were sufficient to induce eosinophilia in the lungs, lung $\mathrm{CDC} 1$ s obtained from OVA aerosol challenged mice were i.t. injected into OVA-sensitized mice, as indicated in Fig. 2l. Control mice received a saline injection. The results showed that adoptive transfer of $\mathrm{cDC} 1 \mathrm{~s}$ is sufficient to induce eosinophilia in the lungs of sensitized mice compared with those in the saline group (Fig. 2l). In a similar experimental setting, injecting lung $\mathrm{CD} 24^{+} \mathrm{cDC} 2 \mathrm{~s}$ and MCs from OVAchallenged mice showed less eosinophil infiltration in the lungs (Fig. 2l). These data suggested that lung $\mathrm{cDCls}$ from OVAchallenged mice during the memory stage were both necessary and sufficient for the induction of lung eosinophilia by directly attracting eosinophils.

Lung cDC1s recruit eosinophils by CCL17 and CCL22. How cDC1s recruit eosinophils remains to be elucidated. The number of cDC1s increased steadily until day 4.5 after OVA challenge (Supplementary Fig. 10a). We hypothesized that lung cDC1s

Fig. 1 Lung DCs are required for eosinophil recruitment during allergen challenge. a Mice model of kinetics of eosinophil recruitment. b, c FACS (b) and total numbers (c) of eosinophil recruitment in different lung compartments in the murine kinetics model of allergic inflammation shown in a. Upper row, lung tissue homogenates; lower row, Balf. $n=4-8$ mice per group. d Protocol for in vivo recruitment assay (air-pouch assay). e Counts of eosinophils recruited into the air pouches of wild-type (WT) mice injected with lung CD45- cells or CD45+ cells (left), lung CD4+ ${ }^{+}$cells (middle), or ILC2s (right) were analyzed by FACS. $n=5-7$ mice per group. $\mathbf{f}-\mathbf{h}$ Eosinophil recruitment of allergic CD11c-DTR Tg (empty circle) or WT (solid circle) mice i.t. injected with DT to delete lung CD11c ${ }^{+}$DCs and AMs, where $\mathbf{f}$ shows the protocol. $\mathbf{g}$ Different deletion efficiencies of DCs and AMs in the lung of CD11c-DTR Tg or WT mice after i.t. instillation with DT. $\mathbf{h}$ Total numbers of eosinophils in the lung or Balf. $n=4$ mice (Saline) or $n=6$ mice (OVA). $\mathbf{i}-\mathbf{k}$ Eosinophil recruitment of allergic C57BI/6 mice i.t. injected with clodronate liposome (CLL) (empty circle) or control (solid circle) on day -1.5 to delete lung AMs, where $\mathbf{i}$ presents the protocol. $\mathbf{j} 24 \mathrm{~h}$ after CLL or empty liposome instillation, lungs were analyzed for the presence of AMs. $\mathbf{k}$ The total numbers of eosinophils in the lung or Balf. $n=4$ mice (Saline) or $n=8$ mice (OVA). I Counts of eosinophils recruited into the air pouches of WT mice injected with pulmonary SiglecF ${ }^{-}$CD11 $c^{+} \mid \mathrm{A} / \mathrm{IE}^{+}$DCs or SiglecF ${ }^{+} \mathrm{CD} 11 \mathrm{c}^{\text {high }} \mathrm{AMs}\left(5 \times 10^{4}\right.$ cells, $\left.200 \mu \mathrm{l}\right)$ from OVA-challenged mice. $n=4-5$ mice per group. ${ }^{\star} P<0.05$, ${ }^{\star \star} P<0.01,{ }^{\star \star \star} P<0.001$, unpaired Student's $t$ test. Means \pm SD are shown. Data represent two $(\mathbf{a}-\mathbf{c})$ and three (d-i) independent experiments 
a

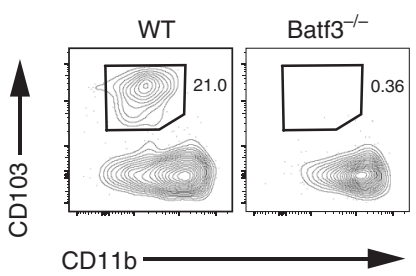

CD11b

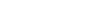

b

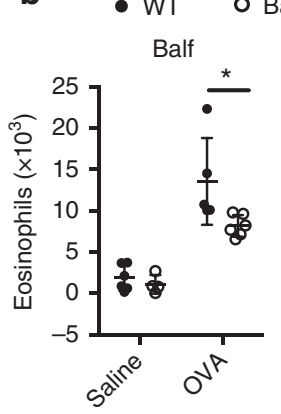

c

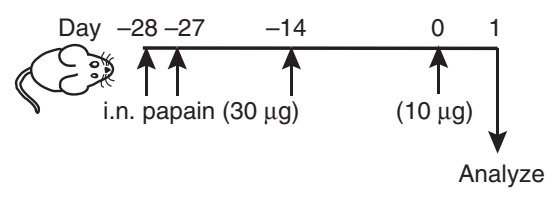

f

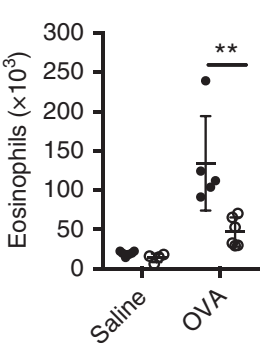

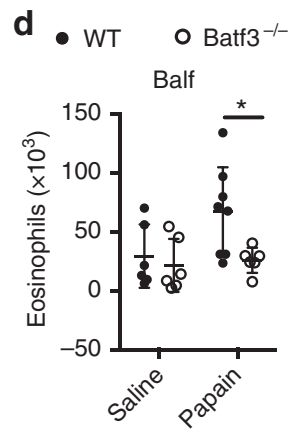

g

- WT O Langerin-DTR Balf

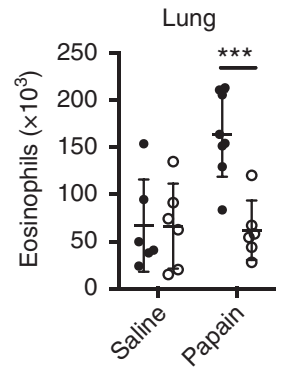

e

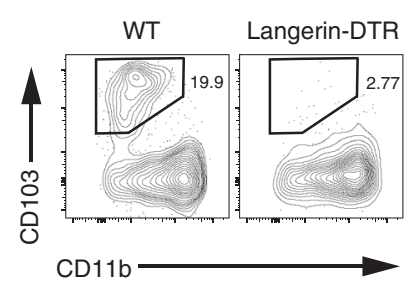

- WT O Langerin-DTR

Balf Lung

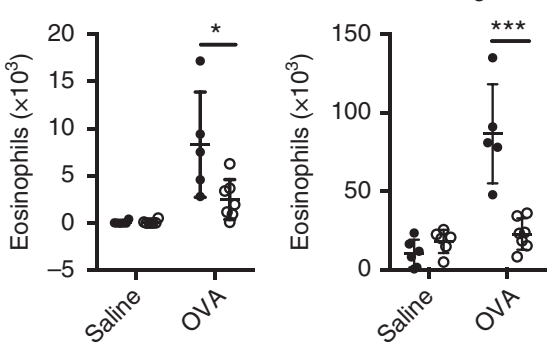

$\mathbf{h}$

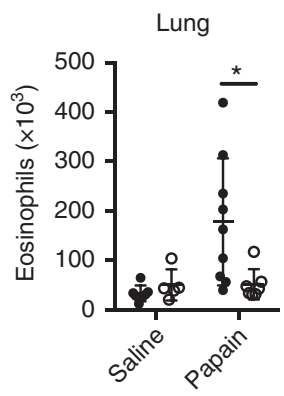

i
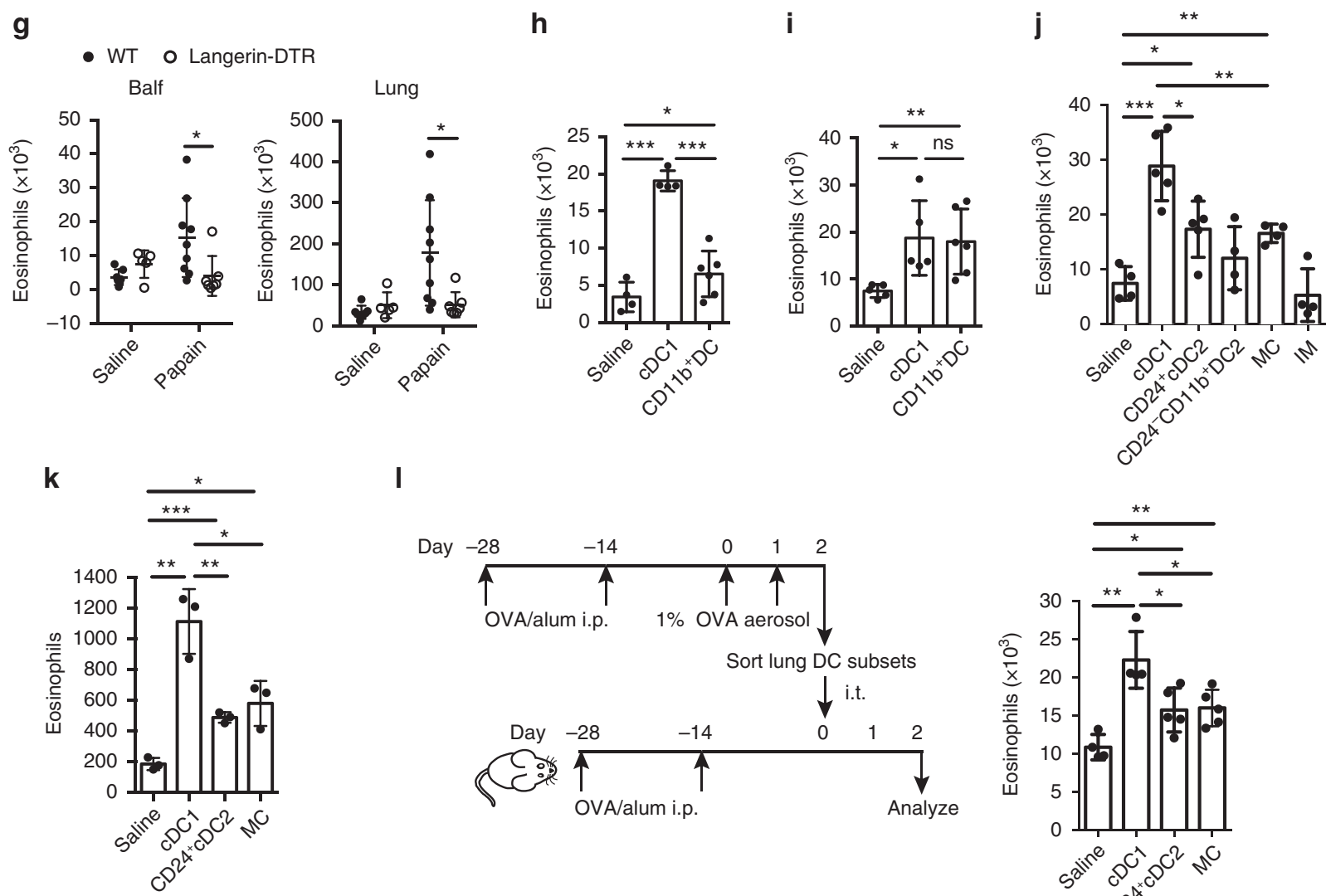

I
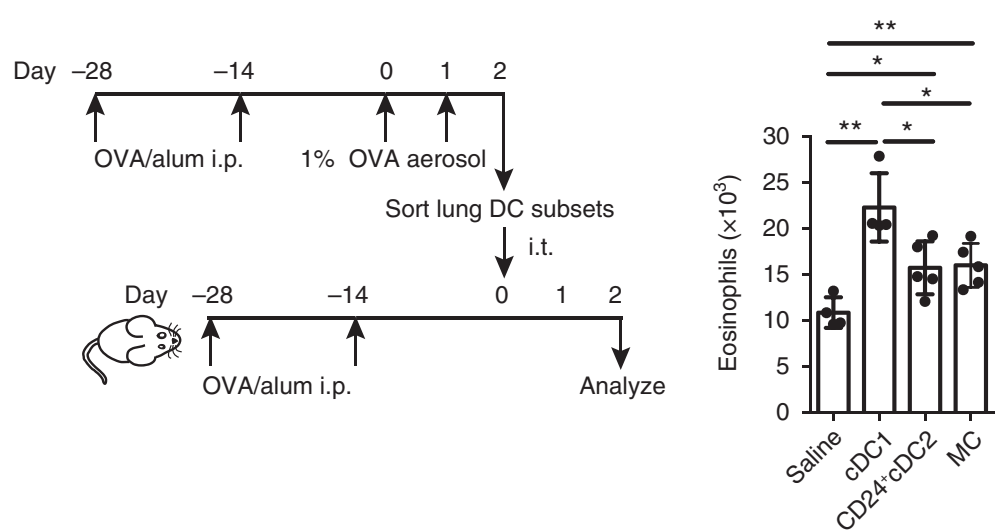

from OVA aerosol challenged mice might secrete chemokines to directly recruit eosinophils. To test this, different subsets of lung DCs and macrophages were sorted from the lungs of OVA- or saline-challenged mice (gating strategy presented in Supplementary Fig. 8) and analyzed for mRNA levels of various chemokines by Q-PCR. cDC1s are not a major source of classical eosinophil recruiting chemokines CCL11 and CCL24. But CCL17 and
CCL22 were prominently expressed by lung cDC1s (Fig. 3a), which is in agreement with a published study ${ }^{25}$. It has been demonstrated that CCL17 and CCL22 have the potential to recruit Th2 cells, cutaneous lymphocyte antigen (CLA)-positive skin-homing $\mathrm{T}$ cells and Treg cells that express CCR4, a highly specific receptor for those 2 chemokines ${ }^{44,45}$. As CCL17 and CCL22 have been rarely suggested to attract eosinophils ${ }^{3,46,47}$, we 
Fig. 2 Lung cDC1s are necessary and sufficient for the induction of eosinophilia. a Lung cDC1s from WT and Batf3 ${ }^{-/-}$mice. $\mathbf{b}$ Eosinophil counts in the lung or Balf in WT (solid circle) and Batf3-/- (empty circle) mice 1.5 days after the first OVA challenge. $n=4$ or 6 mice (Saline) or $n=5-6$ mice (OVA). c, d Mice were sensitized and challenged with papain, and eosinophils in the lung or Balf in WT (solid circle) and Batf $3^{-/-}$(empty circle) mice were analyzed. $n=5-7$ mice per group. e Lung cDC1s from DT treatment langerin-DTR or WT mice. $\mathbf{f}, \mathbf{g}$ OVA/alum-sensitized (f) or papain-sensitized (g) langerin-DTR (empty circle) or WT (solid circle) mice were treated with DT on day -1 , and eosinophils in the lung or Balf were assessed after challenge. $n=5-9$ mice per group. $\mathbf{h}$, i Eosinophils recruited into the air pouches injected with pulmonary $\mathrm{CDC1s}$ (SiglecF $\mathrm{F}^{-} \mathrm{CD} 11 \mathrm{c}^{+} \mathrm{IA} / \mathrm{IE}^{+} \mathrm{CD} 103^{+} \mathrm{CD} 11 \mathrm{~b}^{-}$) or $\mathrm{CD} 11 \mathrm{~b}^{+}$ DCs $\left(1.5 \times 10^{4}, 200 \mu \mathrm{l}\right)$ sorted from C57BL/6 mice 1.5 days after the first OVA challenge $(\mathbf{h})$ or 1 day after the first papain challenge $(\mathbf{i}) . n=4-6$ mice per group. j Eosinophils recruited into the air pouches injected with pulmonary cDC1s, CD24 ${ }^{+} \mathrm{cDC2s}, \mathrm{CD} 24^{-} \mathrm{CD} 11 \mathrm{~b}^{+} \mathrm{DC} 2 \mathrm{~s}, \mathrm{MCs}$, or IMs $\left(1.5 \times 10^{4}, 200 \mu \mathrm{l}\right)$ sorted from C57BL/ 6 mice 1.5 days after the first OVA challenge. $n=4-6$ per group. $\mathbf{k}$ The direct chemotactic effect of lung $c D C 1 s$, CD24+ $c D C 2 s$, or $M C s$ (from C57BL/ 6 mice 1.5 days after the first OVA challenge) on eosinophils was evaluated in a transwell culture system. $n=3-4$ per group. I Protocol (left) and lung eosinophil counts (right) of allergic airway induction by adoptive i.t. injection of lung $C D C 1 s, C D 24+C D C 2 s$, or $M C s$; see Methods ${ }^{\star} P<0.05$, ${ }^{\star \star} P<0.01,{ }^{\star \star \star} P<0.001$, unpaired Student's $t$ test. Means \pm SD are shown. Data represent two $(\mathbf{c}, \mathbf{d}, \mathbf{g}, \mathbf{i}, \mathbf{I})$ and three $(\mathbf{a}, \mathbf{b}, \mathbf{e}, \mathbf{f}, \mathbf{h}, \mathbf{j}, \mathbf{k})$ independent experiments

sought to test whether these 2 chemokines have the chemotactic effect to recruit eosinophils directly. First, we examined whether CCR4 is expressed on the surface of eosinophils by FACS. We found that CCR4 was indeed expressed on eosinophils (Fig. 3b). Then, both in an air pouch and a transwell system, we observed that CCL17 and CCL22 recruit eosinophils directly (Fig. 3c, d).

To examine whether lung $\mathrm{cDC} 1 \mathrm{~s}$ from OVA-challenged mice recruit eosinophils via releasing CCL17 and CCL22, air-pouch assay was performed. As shown in Fig. 3e, eosinophil recruitment mediated by $\mathrm{CDC} 1 \mathrm{~s}$ was completely blocked by anti-CCL17 or anti-CCL22 antibody, suggesting that $\mathrm{CDC} 1 \mathrm{~s}$ recruit eosinophils by secreting CCL17 and CCL22. However, we observed that neutralization of either CCL17 or CCL22 was sufficient to fully abrogate eosinophil recruitment in vivo. Considering that the concentration of CCL17 or CCL22 produced by injected $\mathrm{CDC} 1 \mathrm{~s}$ in the air pouches may be very low, this result suggested that physiological CCL17 and CCL22 should synergize to recruit eosinophils. This hypothesis is supported by an experiment (Supplementary Fig. 11) in which low doses of CCL17 and CCL22 were used and injected into air pouches alone or combined. Only the combination group recruited eosinophils, and neither of them attracted eosinophils alone (Supplementary Fig. 11).

We wished to know whether depletion of lung $\mathrm{CDC} 1 \mathrm{~s}$ could reduce CCL17 and CCL22 levels in the Balf of challenged mice. As expected, on day 1.5 after the first challenge, the level of CCL17 and CCL22 in the Balf was significantly decreased in langerin-DTR mice depleted of $\mathrm{cDCls}$ (Fig. 3f). These data suggested that $\mathrm{CDC} 1$ s may be an important source of CCL17 and CCL22 in the lumen of airways of OVA-challenged mice. Taken together, the above data demonstrated that lung $\mathrm{cDC} 1 \mathrm{~s}$ recruit eosinophils by secreting CCL17 and CCL22.

$\mathrm{CD}^{-} \mathrm{CD}^{-} \mathrm{Cb}^{+}$DC2s promote eosinophil recruitment by cDC1. We sought to investigate how $\mathrm{CDC1}$-mediated eosinophil migration is modulated. It has been suggested that NO plays a key role in allergic asthma. Specifically, NO synthesized by inducible nitric oxide synthase (iNOS, also named $\mathrm{NOS}_{2}$ ) appears to promote eosinophil infiltration into the lungs in an OVA/alum model ${ }^{48-50}$. However, the mechanism by which iNOS-synthesized NO promotes allergic eosinophil influx is poorly understood. To investigate this, we first used $\mathrm{NOS}_{2}{ }^{-1-}$ mice to examine whether inducible NO was regulating eosinophil recruitment in our system. On day 1.5 post first OVA challenge, eosinophil number in both the lungs and Balf of $\mathrm{NOS}_{2}{ }^{-1}$ mice was significantly decreased (Fig. 4a). To test whether blocking NO production before challenge could inhibit eosinophil infiltration, $N$-[3-(aminomethyl)benzyl] acetamidine $(1400 \mathrm{~W})$, a selective iNOS inhibitor, was used. We found that $1400 \mathrm{~W}$ treatment significantly suppressed eosinophil infiltration in the Balf and lung (Fig. 4b).
To determine the relative contribution of iNOS-synthesized NO on lung stromal cells versus hematopoietic cells in response to OVA aerosol challenge, we generated radiation-induced chimeric mice, as indicated in Fig. 4c. Eosinophils in the Balf of mice 1.5 days after the first OVA challenge were detected by FACS. We found that expression of iNOS in hematopoietic cells was critical for eosinophil recruitment, since $\mathrm{NOS}_{2}{ }^{-1-} \rightarrow \mathrm{WT}$ chimeric mice failed to recruit eosinophils in response to OVA aerosol challenge (Fig. 4c).

To determine the major source of $\mathrm{NO}$ in the lung hematopoietic cells, we sorted lung $\mathrm{CD} 45^{+}$cells from OVA-challenged mice and cultured them at $37^{\circ} \mathrm{C}$ for $48 \mathrm{~h}$. We found that nitrite was detectable in the supernatant of cultures of $\mathrm{CD} 45^{+}$lung cells (Fig. 4d). To determine which hematopoietic cell in the lung was the main NO producer, we purified different types of $\mathrm{CD} 45^{+}$cells from the lungs of these mice by FACS and performed Q-PCR assays. As shown in Fig. 4e, we found that CD11b ${ }^{+}$DCs (SiglecF ${ }^{-} \mathrm{CD} 11 \mathrm{c}^{+} \mathrm{IA} / \mathrm{IE}^{+} \mathrm{CD} 103^{-} \mathrm{CD} 11 \mathrm{~b}^{+}$) were the major NO producer (Fig. 4e). To determine which lung $\mathrm{CD}_{11 \mathrm{~b}^{+}} \mathrm{APC}$ subsets produced $\mathrm{NO}$, we purified different $\mathrm{CD}_{11 b^{+}} \mathrm{APC}$ subsets from OVA-challenged mice by FACS and conducted a Q-PCR assay. We found that $\mathrm{CD} 24^{-} \mathrm{CD} 11 b^{+} \mathrm{DC} 2 \mathrm{~s}$ were the major $\mathrm{NO}$ producer (Fig. 4f). By Griess assay, we also found that NO was preferentially produced by $\mathrm{CD} 24^{-} \mathrm{CD} 11 \mathrm{~b}^{+} \mathrm{DC} 2 \mathrm{~s}$, but not by cDC1s, CD24 ${ }^{+}$cDC2s, AMs, or IMs (Fig. 4g). This result was further supported by FACS analysis (Fig. 4h).

Considering that NO promotes eosinophil infiltration and that $\mathrm{CD} 24^{-} \mathrm{CD} 11 \mathrm{~b}^{+} \mathrm{DC} 2 \mathrm{~s}$ were the main source of $\mathrm{NO}$ in the lung after challenge, we hypothesized that $\mathrm{CD} 24^{-} \mathrm{CD} 11 \mathrm{~b}^{+} \mathrm{DC} 2 \mathrm{~s}$ could promote $\mathrm{cDC} 1$-mediated eosinophil infiltration via NO. To test this, air-pouch assay was performed as indicated in Fig. 4i. Both WT and $\mathrm{KO} \mathrm{CD}_{24}{ }^{-} \mathrm{CD} 11 \mathrm{~b}^{+} \mathrm{DC} 2 \mathrm{~s}$ did not display any capacity to recruit eosinophils. However, compared to WT cDC1s alone, the eosinophil number in the air pouches was significantly increased if WT cDC1s were injected together with WT CD24-CD11b ${ }^{+}$DC2s (Fig. 4i). These data suggested that $\mathrm{CD} 24^{-} \mathrm{CD} 11 \mathrm{~b}^{+}$DC2s indeed promoted $\mathrm{CDC1}$-mediated eosinophil infiltration. Interestingly, the results also showed that the WT $\mathrm{CDC1}$-mediated eosinophil recruitment effects can be enhanced by WT $\mathrm{CD} 24^{-} \mathrm{CD} 11 \mathrm{~b}^{+}$ DC2s but not $\mathrm{KO} \mathrm{CD} 24^{-} \mathrm{CD} 11 \mathrm{~b}^{+} \mathrm{DC} 2 \mathrm{~s}$, suggesting that $\mathrm{NO}$ from $\mathrm{CD} 24^{-} \mathrm{CD} 11 \mathrm{~b}^{+} \mathrm{DC} 2 \mathrm{~s}$ is critical for $\mathrm{cDC} 1$-initiated eosinophil infiltration (Fig. 4i). This result further suggested that $\mathrm{CD}_{24}{ }^{-} \mathrm{CD} 11 \mathrm{~b}^{+}$DC2-derived $\mathrm{NO}$ is essential for $\mathrm{CDC} 1 \mathrm{~s}$ to initiate eosinophil recruitment, which is partially supported by the fact that $\mathrm{CD} 24^{-} \mathrm{CD} 11 \mathrm{~b}^{+} \mathrm{DC} 2 \mathrm{~s}$ were also significantly depleted in CD11cDTR mice (Supplementary Fig. 12), which showed that lung $\mathrm{CD}_{11 \mathrm{c}^{+}} \mathrm{APCs}$ were required for the recruitment of eosinophils in response to OVA challenge. Taken together, the above data demonstrated that $\mathrm{CD} 24^{-} \mathrm{CD} 11 \mathrm{~b}^{+}$DC2s indeed promoted $\mathrm{cDC} 1-$ mediated eosinophil infiltration by producing NO. 
a Saline

- OVA

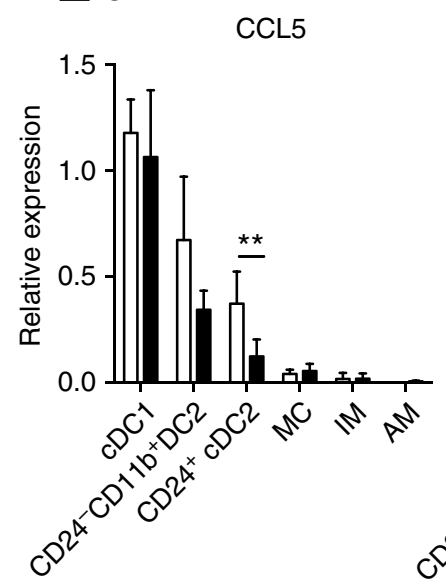

CCL8

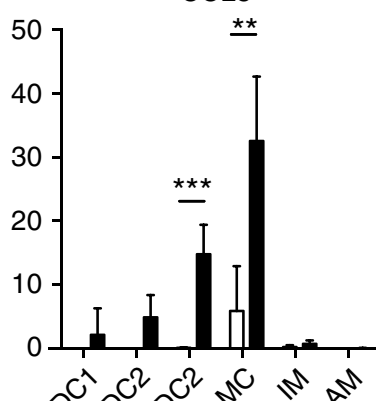

CCL17
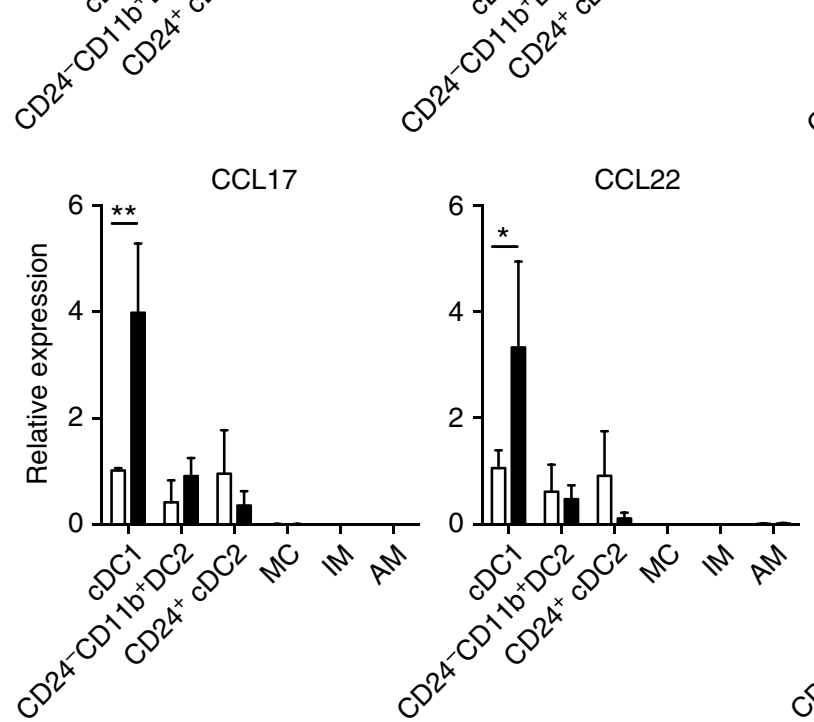

b

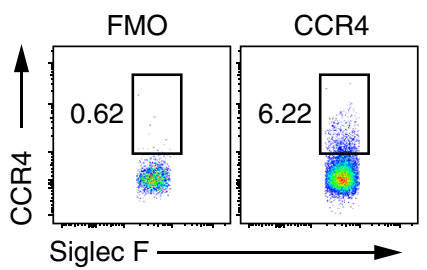

d

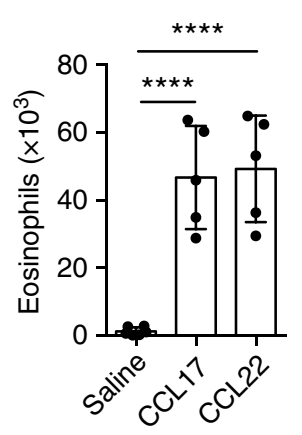

e

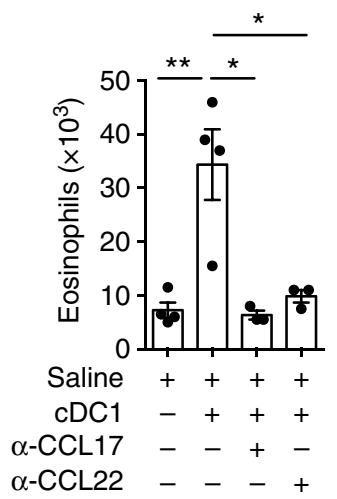

CCL11
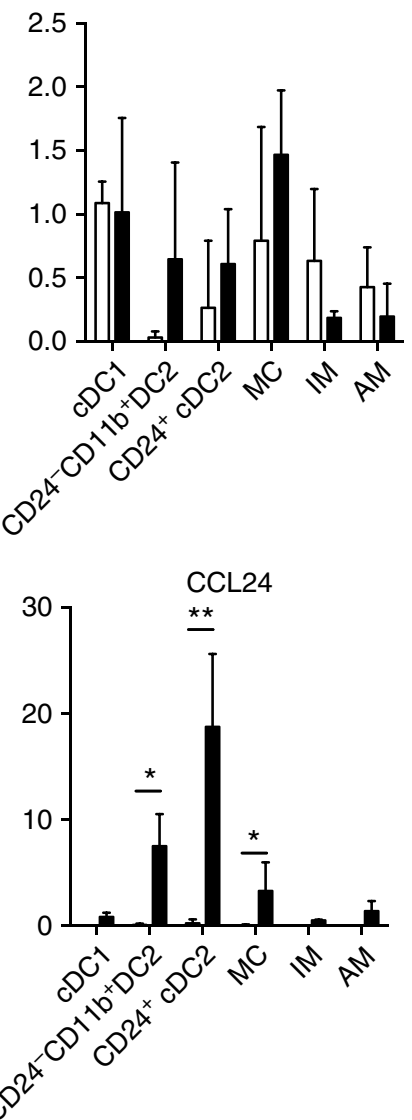

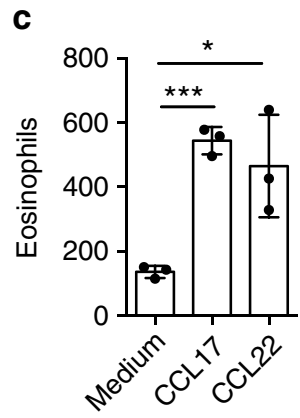

Fig. 3 Lung CDC1s directly recruit eosinophils via CCL17 and CCL22. a mRNA expression of CCL5, CCL8, CCL11, CC117, CCL22, and CCL24 chemokines by lung cDC1s, CD24+ $c D C 2 s, C D 24-C D 11 b+D C 2 s, M C s$, IMs, and AMs isolated from mice 1.5 days after the first OVA challenge. mRNA expression was first normalized against the housekeeping GAPDH genes and then represented as relative expression compared to the $c D C 1 \mathrm{~s}$ from saline-treated mice. $n=3-4$ mice per group. b FACS analysis of CCR4 expression on lung eosinophils from naive C57BI/6 mice. c The direct chemotactic effect of CCL17 (100 pg per $\mathrm{ml}$ ) and CCL22 (100 pg per $\mathrm{ml}$ ) on eosinophils was evaluated in a transwell culture system. $n=3$ per group. d Counts of eosinophils recruited into the air pouches of wild-type mice $5 \mathrm{~h}$ after injection of CCL17 (150 pg) or CCL22 (150 pg) with $500 \mu$ l of temperature-sensitive surface gel. $n=5-6$ mice per group. e Counts of eosinophils recruited into the air pouches of wild-type mice injected with pulmonary $\mathrm{CDC}$ (s $\left(\mathrm{SiglecF} \mathrm{F}^{-} \mathrm{CD} 11 \mathrm{c}^{+} \mid \mathrm{A} / \mathrm{IE} \mathrm{E}^{+} \mathrm{CD} 103^{+} \mathrm{CD} 11 \mathrm{~b}^{-}\right.$) from OVA-challenged C57BI/6 mice with CCL17 or CCL22 neutralizing antibody or goat lgG isotype control. $n=3-4$ mice per group. $\mathbf{f}$ ELISA analysis of CCL17 and CCL22 in Balf supernatant from DT-treated langerin-DTR (empty rectangle) or wild-type (solid rectangle) mice 1.5 days after the first OVA challenge. $n=5-7$ mice per group. ${ }^{\star} P<0.05,{ }^{\star \star} P<0.01,{ }^{\star \star \star} P<0.001$, unpaired Student's $t$ test. Means \pm SD are shown. Data represent two (a, b, $\left.\mathbf{d}, \mathbf{e}, \mathbf{f}\right)$ and three (c) independent experiments 


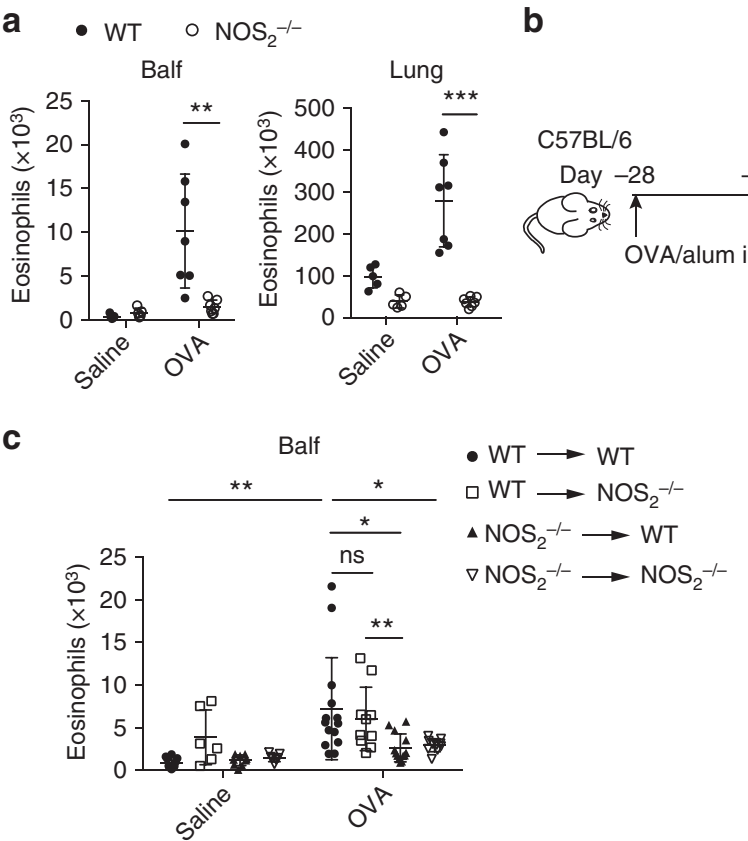

$\mathbf{f}$

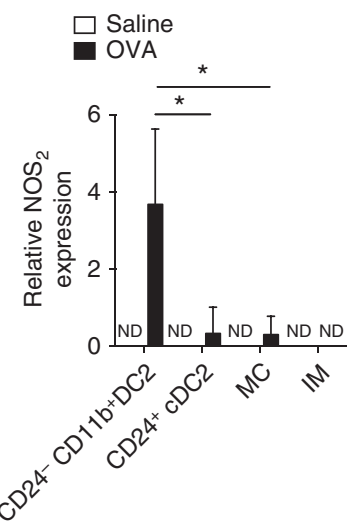

g

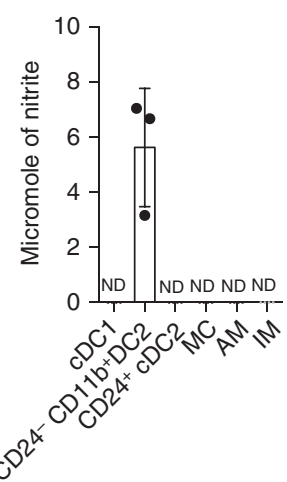

i.p. $1400 \mathrm{~W}$ or control

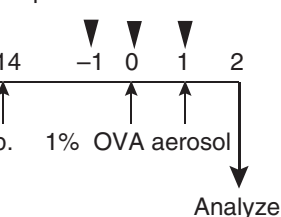

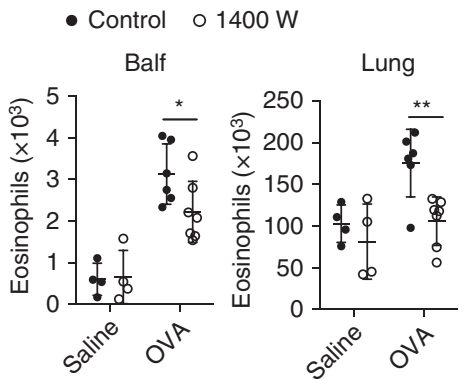

d e

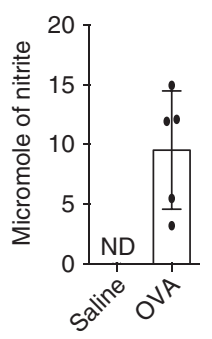

h

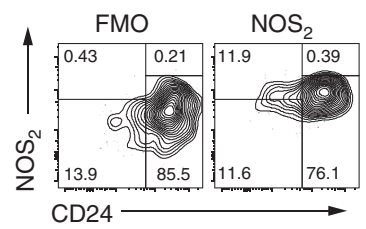

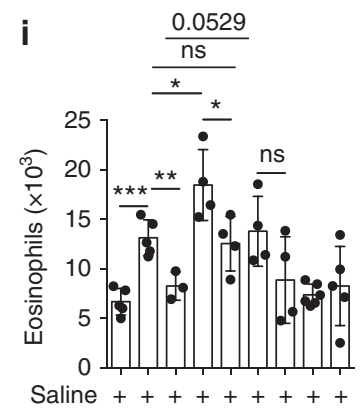

WT CDC1 $-++++\cdots+-$

WT CD24-CD11b+DC2 - - + + + + +

$\mathrm{KO} \mathrm{CDC} 1-++\cdots++--$

$\mathrm{KO}$ CD24-CD11b+DC2 - - - + + + +

\section{j}

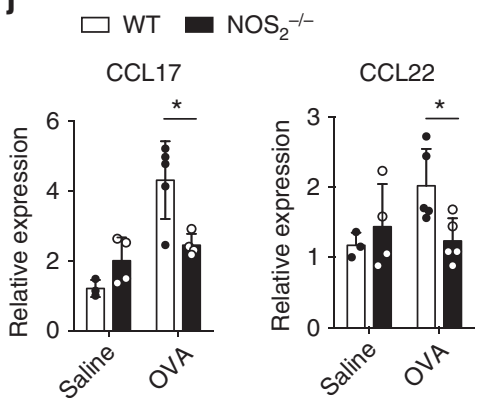

We next sought to determine whether the effect of NO might have been achieved through modulating CCL17 and CCL22 expression by lung CDC1s. To test this, the expression of CCL17 and CCL22 in lung $\mathrm{CDC} 1 \mathrm{~s}$ from $\mathrm{NOS}_{2}{ }^{-1-}$ mice or wild type mice 1.5 days after the first OVA challenge was analyzed by Q-PCR. As shown in Fig. 4j, CCL17 and CCL22 expression was significantly decreased in lung $\mathrm{CDCls}$ of $\mathrm{NOS}_{2}{ }^{-1-}$ mice compared to those from control mice. Taken together, these data suggested that lung $\mathrm{CD} 24^{-} \mathrm{CD} 11 \mathrm{~b}^{+}$DC2s promote $\mathrm{cDC} 1-$ mediated eosinophil infiltration through NO.
Lung $\mathrm{CD}^{+} \mathrm{cDC}^{+} \mathrm{s}$ inhibit cDC1-mediated eosinophil migration. The data shown in Fig. 1c revealed that on day 2.5 after the first OVA challenge there was a turning point, which suggested that an anti-inflammatory factor starts to shut down the inflammation. Considering that TGF- $\beta 1$ is an important anti-inflammatory cytokine and that lung $\mathrm{CD}_{11 \mathrm{c}^{+}} \mathrm{DCs}$ are critical for eosinophil recruitment, we postulated that if TGF$\beta 1$ was selectively depleted in $\mathrm{CD}_{11 c^{+}}$cells, it might lead to increased infiltration of eosinophils on day 2.5 after the first OVA challenge. To test this, TGF- $\beta 1^{\mathrm{fl} / \mathrm{fl}} C D 11 c^{\mathrm{cre}}$ mice were 
Fig. 4 Lung CD24-CD11b+ DC2s promote CDC1-mediated eosinophil recruitment. a-c Mice were sensitized and challenged with OVA and culled 1.5 days after the first OVA challenge, and eosinophil counts in the lung or Balf were assessed. a WT (solid circle) and NOS $_{2}{ }^{-/-}\left(e^{-m p t y ~ c i r c l e) ~ m i c e . ~} n=5-7\right.$. b $1400 \mathrm{~W}$ (empty circle) or control-treated (solid circle) mice, protocol on the left. $n=4-7$. c $\mathrm{NOS}_{2}{ }^{-/-}$and WT bone marrow chimeric mice. WT to WT (solid circle), WT to $\mathrm{NOS}_{2}{ }^{-1-}$ (empty square), $\mathrm{NOS}_{2}^{-1-}$ to WT (solid triangle), and $\mathrm{NOS}_{2}{ }^{-/-}$to $\mathrm{NOS}_{2}{ }^{-/-}$(empty triangle) mice. $n=6-10$ (Saline) or $n$ $=10-14$ (OVA). $\mathbf{d}$-f Cells were sorted from mice 1.5 days after the first OVA challenge and used for assay. $\mathbf{d}$ NO production measured as nitrite in lung CD $45^{+}$cell culture supernatants. $n=4-5$ per group. e mRNA expression of $N O S_{2}$ by different types of lung CD45 cells, such as CD11b ${ }^{+} D C s$, cDC1s (SiglecF ${ }^{-} \mathrm{CD}_{11} \mathrm{c}^{+} \mathrm{IA} / \mathrm{IE}^{+} \mathrm{CD}_{103}{ }^{+} \mathrm{CD}_{11 b^{-}}$), neutrophils (NEU), etc. $n=3$ per group. $\mathbf{f} \mathrm{NOS}_{2}$ mRNA expression in lung CD24-CD11b+ DC2s isolated from OVA (solid rectangle) or saline (empty rectangle) challenged mice. mRNA expression is shown relative to the expression of NEU (e) or CD24 ${ }^{+} \mathrm{cDC}^{\mathrm{s}} \mathrm{s}$ (f). $n=4$ per group. $\mathbf{g}$ NO production measured in lung CD24-CD11b + DC2 culture supernatants. $n=4$ per group. $\mathbf{h}$ FACS analysis of NOS 2 expression on lung CD11b ${ }^{+}$DCs from OVA-challenge mice. $\mathbf{i}, \mathbf{j}$ Cells were purified from $\mathrm{NOS}_{2}{ }^{-1-}$ or WT mice 1.5 days after the first OVA challenge. $\mathbf{i}$ Eosinophils

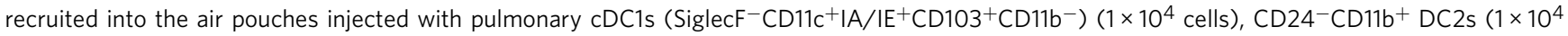
cells). $n=4-6$ per group. $\mathbf{j}$ mRNA expression of CCL17 and CCL22 by lung CDC1s from $N_{2} S_{2}^{-}-$(solid rectangle) or WT mice (empty rectangle). $n=3-5$ per group. ${ }^{\star} P<0.05,{ }^{\star \star} P<0.01,{ }^{\star \star \star} P<0.001$, unpaired Student's $t$ test. Means \pm SD are shown. Data represent two (c, e) and three (a, b, $\left.\mathbf{d}, \mathbf{f}-\mathbf{j}\right)$ independent experiments

used in which the increased TGF- $\beta 1$ expression can be selectively downregulated in lung CD11 $\mathrm{c}^{\text {hi }}$ cells (Supplementary Fig. 13). On day 2.5 after the first OVA aerosol challenge, mice with $\mathrm{CD}_{11 \mathrm{c}^{+}}$cell-specific loss of TGF- $\beta 1$ showed augmented eosinophil infiltration (in lung and Balf) compared with the $T G F-\beta 1^{\mathrm{fl} / \mathrm{fl}}$ controls (Fig. 5a). Importantly, this effect was not seen on day 1.5 (Fig. 5 b).

Next, we sought to determine which $\mathrm{CD} 11 \mathrm{c}^{+}$cells in lung could upregulate the TGF- $\beta 1$ expression. As shown in Fig. $5 \mathrm{c}$, the data revealed that the expression of TGF- $\beta 1$ in $\mathrm{CD} 24^{+} \mathrm{cDC} 2 \mathrm{~s}$ was significantly upregulated, but not in other DC or macrophage subsets (Fig. $5 \mathrm{c}$ ). And the induced expression of TGF- $\beta 1$ in CD24 $4^{+}$ $\mathrm{cDC} 2 \mathrm{~s}$ was only observed on day 2.5 , but not on day 1.5 , although the cell number of $\mathrm{CD} 24^{+} \mathrm{cDC} 2$ was increased steadily after OVA aerosol challenge (Fig. 5d, e). Then, we sought to determine whether $\mathrm{CD} 24^{+} \mathrm{cDC} 2 \mathrm{~s}$ inhibit $\mathrm{cDC} 1$-mediated eosinophil infiltration, and if so, whether this inhibitory effect is mediated by TGF- $\beta 1$. For this investigation, mice were culled on day 2.5 after the first OVA challenge, and lung $\mathrm{CD} 24^{+} \mathrm{cDC} 2 \mathrm{~s}$ with $\mathrm{cDC} 1 \mathrm{~s}$ were put together in air pouches. We found the $\mathrm{CDC} 1$-mediated eosinophil infiltration in the air pouches was significantly reduced (Fig. 5f). Notably, this inhibitory effect could be reversed by adding $\alpha$-TGF- $\beta 1$ antibody into an air pouch (Fig. 5f). These data demonstrated that the inhibitory effect of $\mathrm{CD} 24^{+} \mathrm{cDC} 2 \mathrm{~s}$ on $\mathrm{cDC} 1$-mediated eosinophil recruitment was mediated by TGF- $\beta 1$. To further confirm this, we injected CD $24^{+}$cDC2s from TGF- $\beta 1^{\mathrm{fl} / \mathrm{fl}} C D 11 c^{\mathrm{cre}}$ mice or $T G F-\beta 1^{\mathrm{fl} / \mathrm{fl}}$ mice together with $\mathrm{cDC} 1 \mathrm{~s}$ into the air pouches. We found that the CD24 ${ }^{+}$cDC2 loss of TGF- $\beta 1$ did not suppress the $\mathrm{cDC} 1$-mediated eosinophil infiltration anymore (Fig. $5 \mathrm{~g}$ ). We also found that CCL17 and CCL22 production by lung CDC1s from TGF- $\beta 1^{\mathrm{fl} / \mathrm{fl}} C D 11 c^{\mathrm{cre}}$ mice significantly increased compared to control mice on day 2.5 after the first OVA aerosol challenge (Fig. 5h), indicating that the expression of CCL17 and CCL22 was regulated by TGF- $\beta 1$ from $\mathrm{CD} 24^{+}$cDC2s. Taken together, our data suggested that during the late eosinophil infiltration phase after inhaled OVA challenge (day 2.5 after the first OVA aerosol challenge), lung CD24 ${ }^{+} \mathrm{cDC} 2 \mathrm{~s}$ suppressed lung $\mathrm{CDC1}$-mediated eosinophil infiltration by secretion of TGF- $\beta 1$.

Collectively, these data reveal that different lung DC subsets modulate cDC1-mediated eosinophil recruitment dynamically by secreting distinct soluble factors during the memory stage of chronic asthma after allergen challenge in mice (Fig. 6).

\section{Discussion}

How eosinophils are initially recruited to the lung tissue and airway during the memory phase of chronic allergic asthma after allergen challenge is largely unknown. Although both $\mathrm{CD}^{+} \mathrm{T}$ and ILC2s appear to play roles in eosinophilic asthma ${ }^{5,51}$, neither of them shows any capacity to attract eosinophil by themselves on day 1.5 after the first OVA challenge (Fig. 1e). Our results showed that DCs are capable of directly attracting eosinophils, and they are essential for the initial eosinophil accumulation after allergen challenge.

Our results demonstrated that in a chronic asthma model, eosinophil infiltration was impaired in cDC1-deficient Batf3-lmice in response to inhaled OVA or papain challenge. Depletion of $\mathrm{CDC} 1 \mathrm{~s}$ immediately before the challenge in langerin-DTR mice also decreased eosinophil infiltration both in OVA/alum or papain-induced chronic asthma during the memory stage. The fact that $\mathrm{CDC} 1 \mathrm{~s}$ were essential for type 2 airway inflammation in response to OVA or papain allergen challenge seems to contradict a prior publication 25,26 , which showed that during the challenge phase $\mathrm{cDC1} 1 \mathrm{~s}$ are not required for dust mite (Blomia tropicalis or Dermatophagoides pteronyssinus)-induced allergic airway inflammation. The explanation for these discrepancies could be that the experimental models are fundamentally different, with different sensitization/challenge protocols performed. In the acute "dust mite model"25,26, cDC1s were ablated by DT treatment in naive langerin-DTR animals before allergen sensitization, and then animals were challenged on day 7 or 9 after the first sensitization, a time point at which more than $64 \%$ of $\mathrm{cDC} 1 \mathrm{~s}$ were recovered from depletion (Supplementary Fig. 7). Thus, these results actually reflect the contribution of $\mathrm{cDCl}$ s to the primary immune response. On the other hand, in the current study, a chronic model was used, and mice were challenged 28 days later after the first sensitization, and the influence of $\mathrm{cDC1}$ s on eosinophil infiltration on day 1.5 after the first challenge was examined, which reflects the role of $\mathrm{cDC} 1 \mathrm{~s}$ in memory phase. Thus, it is likely that $\mathrm{CD} 11 \mathrm{~b}^{+} \mathrm{DCs}$ are essential for the primary Th2 response, while $\mathrm{cDC} 1 \mathrm{~s}$ are critical for eosinophil infiltration during memory stage after challenge.

More interestingly, our data showed that lung cDC1s from challenged mice can directly recruit eosinophils. Further, we found that $\mathrm{CDC} 1$ subsets from OVA aerosol challenged mice were sufficient to induce eosinophilia in the lungs of OVA-sensitized mice, which was consistent with published results in which adoptive transfer of DCs is sufficient to induce all asthmatic features in sensitized mice ${ }^{32}$.

We found that lung $\mathrm{CDC} 1 \mathrm{~s}$ expressed high levels of CCL17 and CCL22, but low levels of CCL11 and CCL24 expression, which is consistent with the published literature ${ }^{25}$. Classically, eosinophil recruitment is thought to be driven by eotactic chemokines such as CCL11 and CCL24 4 1,3,12. CCL17 and CCL22 are rarely reported involved in the recruitment of eosinophil. To explore this further, we undertook a series of experiments. First, we demonstrated that CCR4 is expressed on eosinophils, and CCL17 and CCL22 could recruit eosinophils directly (Fig. $3 \mathrm{~b}-\mathrm{d}$ ). Then, we found that blocking CCL17 and CCL22 decreased the eosinophil- 
a<smiles>C[Te]=[Fe]</smiles>

Balf

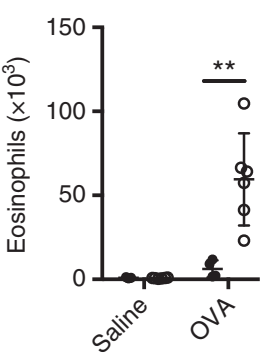

C

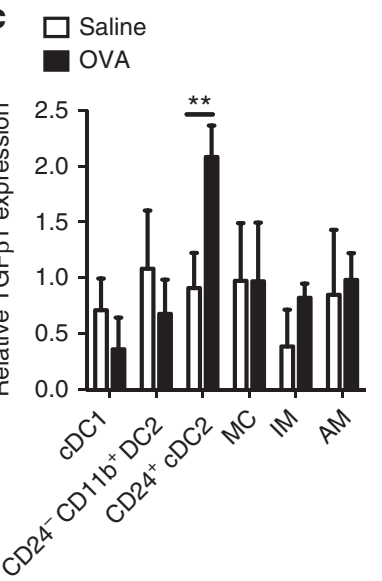

- TGF- $\beta 1^{\mathrm{f} / \mathrm{f}} \mathrm{CD} 11 \mathrm{c}^{\mathrm{cre}}$

Lung b

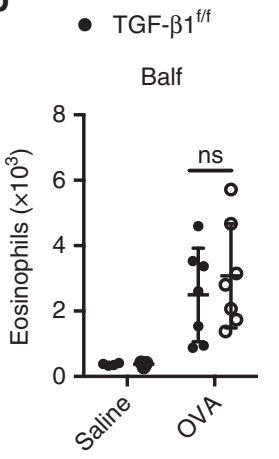

- TGF- $\beta 1^{f / f} \mathrm{CD} 11 \mathrm{c}^{\mathrm{cre}}$

Lung

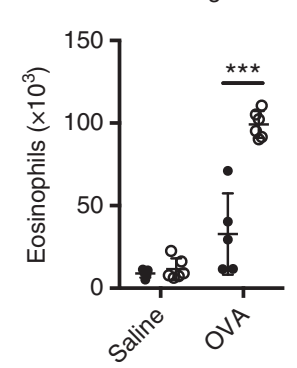

d

e
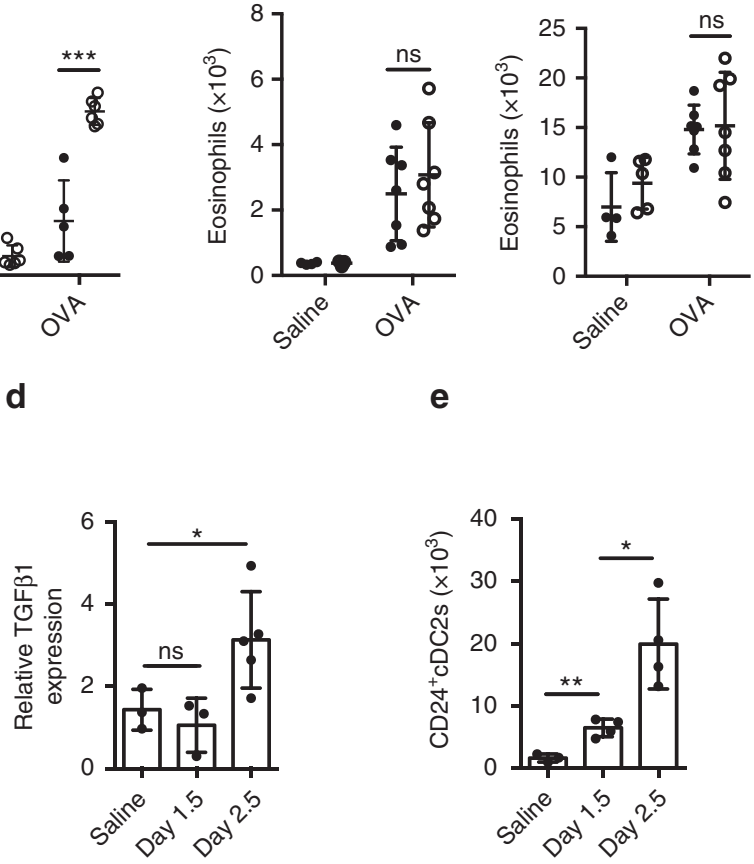

f

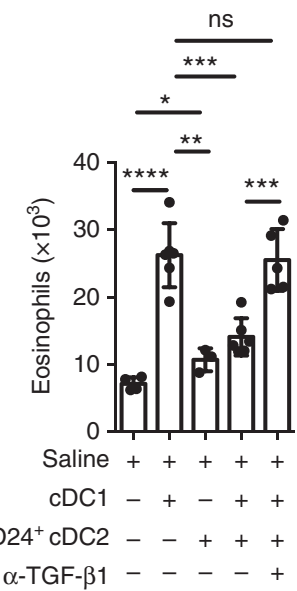

g

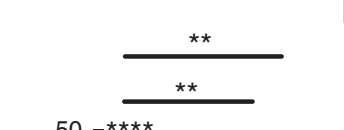

h

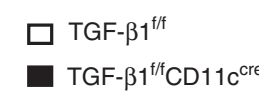

CCL22

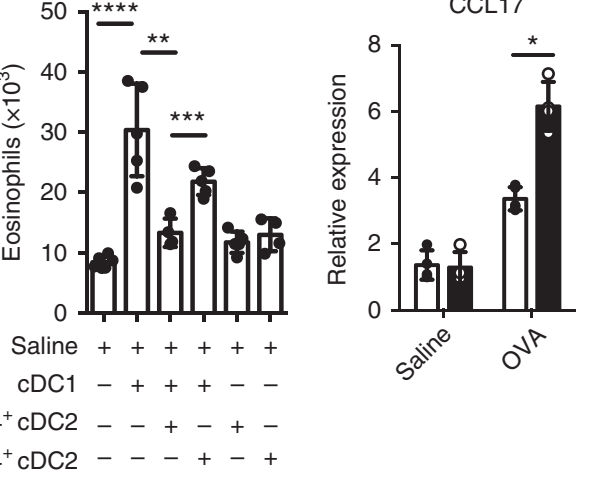

Fig. 5 Lung CD24 ${ }^{+}{ }_{\mathrm{CDC} 2 \mathrm{~s}}$ inhibit $\mathrm{CDC1}$-mediated eosinophil migration via TGF- $\beta 1$. $\mathbf{a}$, b Quantification of eosinophils in Balf and lung from TGF- $\beta 7^{\mathrm{fl} /}$

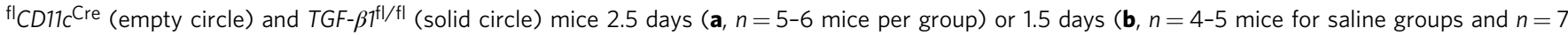
mice for OVA groups) after the first OVA challenge. c mRNA expression of TGF- $\beta 1$ by pulmonary cDC1, CD24+ ${ }^{+} D C 2, C D 24-C D 11 b^{+}$DC2, MC, IM and AM populations separated from C57BL/ 6 mice 2.5 days after the first OVA (solid rectangle) or saline (empty rectangle) challenge. $\mathbf{d}$ mRNA expression of TGF- $\beta 1$ by pulmonary $\mathrm{CD} 24^{+} \mathrm{CDC} 2 \mathrm{~s}$ separated from $\mathrm{C} 57 \mathrm{BL} / 6$ mice $0,1.5$, or 2.5 days after the first OVA challenge. mRNA expression is relative to the expression of $\mathrm{cDC1s}(\mathbf{c})$ or $\mathrm{CD} 24^{-} \mathrm{CD} 11 \mathrm{~b}^{+} \mathrm{DC2s}(\mathbf{d})$ from saline-treated mice. $n=3-5$ per group. e Counts of CD24+ $\mathrm{cDC} 2 \mathrm{~s}$ in lungs from C57BL/6 mice $0,1.5$, or 2.5 days after the first OVA challenge. $\mathbf{f}$ Counts of eosinophils recruited into the air pouches injected with pulmonary $\mathrm{CDC1s}$ or $\mathrm{CD} 24^{+}$ cDC2s $\left(1 \times 10^{4}\right.$ cells, $\left.200 \mu \mathrm{l}\right)$ purified from C57BL/6 mice 2.5 days after the first OVA challenge with anti-TGF- $\beta 1$ (10 $\mu \mathrm{g}$ per ml) antibody or mouse lgG1 isotype control. $n=4-6$ mice per group. $\mathbf{g}$ Counts of eosinophils recruited into the air pouches injected with pulmonary $c D C 1 s$, and $C D 24+c D C 2 s\left(1 \times 10^{4}\right.$

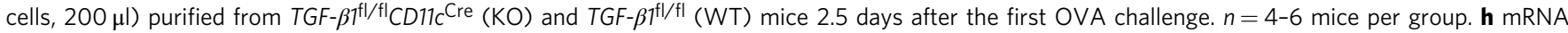

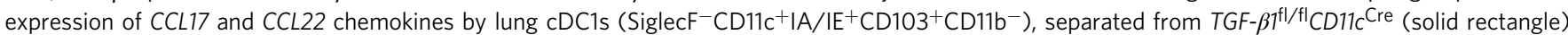
and TGF- $\beta 7^{f l / f l}$ (empty rectangle) mice 2.5 days after the first OVA challenge. $n=4-5$ per group. ${ }^{\star} P<0.05,{ }^{\star \star} P<0.01,{ }^{\star \star \star} P<0.001$, unpaired Student's $t$ test. Means \pm SD are shown. Data represent two $(\mathbf{c}, \mathbf{d})$ and three $(\mathbf{a}, \mathbf{b}, \mathbf{e}-\mathbf{h})$ independent experiments 


\section{Allergen challenge}

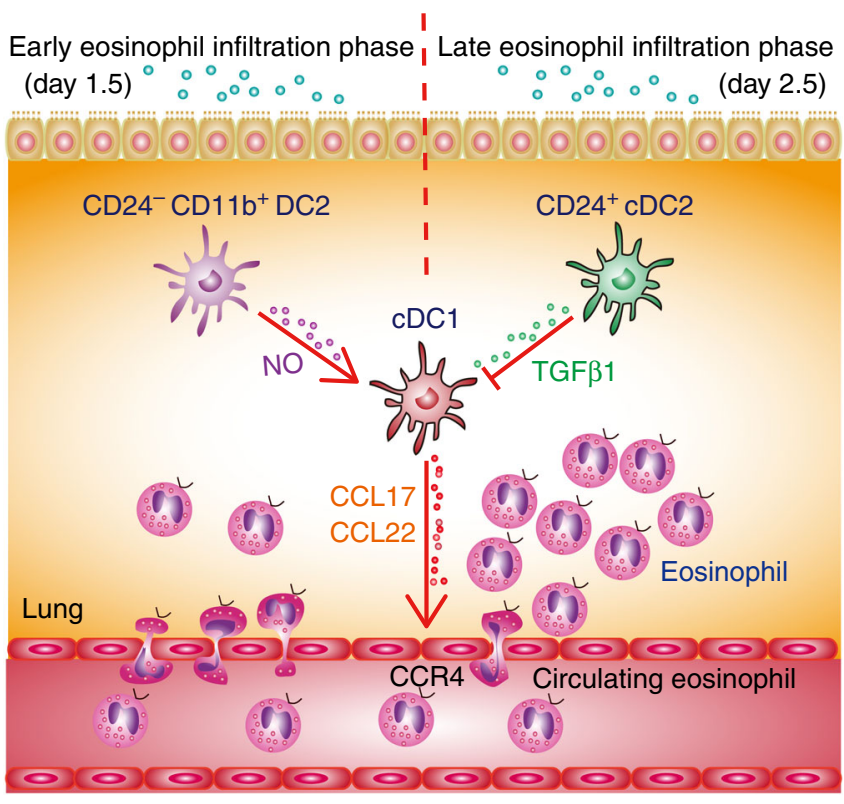

Fig. 6 Initial eosinophil recruitment is dynamically regulated by lung DC subsets. After allergen challenge, $C D C 1$ s directly recruit eosinophils by secreting CCL17 and CCL22, which are critical for early eosinophil infiltration. This CDC1-mediated eosinophil infiltration is dynamically modulated by other lung DC subsets. After allergen challenge, lung CD24-CD11b+ DC2s promoted eosinophil infiltration by producing $\mathrm{NO}$ on day 1.5 , which promotes CCL17 and CCL22 expression by CDC1s, whereas CD24+ ${ }^{+} D C 2 s$ inhibit this process by releasing TGF- $\beta 1$ on day 2.5

recruitment activity of lung $\mathrm{cDC} 1 \mathrm{~s}$ from allergen-challenged mice (Fig. 3e). Third, we demonstrated that after OVA aerosol challenge, the level of CCL17 and CCL22 in the Balf was significantly decreased in mice depleted of $\mathrm{cDC} 1 \mathrm{~s}$ (Fig. 3f). We found that lung CD24 ${ }^{+}$cDC2s and MCs, with the expression of CCL24 (Fig. 3a), displayed the capacity to recruit eosinophils, although their capacity was less than that of cDC1s (Fig. 2j, k). However, while CCL24 was also expressed by CD24-CD11b ${ }^{+}$DC2s (Fig. 3a), they did not show any chemotactic effects (Fig. 2j). A similar phenomenon has also been described in a previous study, in which AM-derived CCL24 is dispensable for IL-13-induced airway inflammation ${ }^{52}$. Although we do not fully understand the reason, it is worth further investigation.

Nevertheless, our data demonstrated a previously unappreciated mechanism that in response to allergen challenge, lung cDC1s attract eosinophils directly through secreting CCL17 and CCL22 during the memory stage in chronic asthma. Considering that eosinophils have been shown to be required for Th2 cell infiltration after allergen challenge via stimulating the production of CCL17 and CCL22 by the lungs ${ }^{8,35}$, we propose a model in which, in response to allergen challenge, $\mathrm{CDC} 1 \mathrm{~s}$ provide the initial CCL17 and CCL22 to recruit the eosinophil infiltration within 2 days, which in turn stimulated more CCL17 and CCL22 production by the lungs to attract Th2 effector cells.

In the current study, we also found that $\mathrm{CD} 24^{-} \mathrm{CD} 11 \mathrm{~b}^{+} \mathrm{DC} 2 \mathrm{~s}$ are capable of producing $\mathrm{NO}$, which plays a key role in promoting eosinophil recruitment after challenge in allergic asthma ${ }^{48-50}$. By using radiation-induced chimeric mice, we found $\mathrm{NO}$ from hematopoietic cells, but not from lung stromal cells, was critical for eosinophil recruitment (Fig. 4c). More importantly, we found that the $\mathrm{CD} 24^{-} \mathrm{CD} 11 \mathrm{~b}^{+} \mathrm{DC} 2 \mathrm{~s}$ population is the major source of $\mathrm{NO}$ in the lungs at the early time point after the first challenge
(Fig. 4f-h). By air-pouch assay, we demonstrated that lung $\mathrm{CD} 24^{-} \mathrm{CD} 11 \mathrm{~b}^{+}$DC2s from OVA-challenged mice were able to promote cDC1-mediated eosinophil infiltration in vivo via NO (Fig. 4i). Moreover, we proved that $\mathrm{NO}$ can act via promoting CCL17 and CCL22 expression in CDC1s (Fig. 4j). Therefore, our data not only revealed a previously unrecognized mechanism of the regulation of lung $\mathrm{CD} 24^{-} \mathrm{CD} 11 \mathrm{~b}^{+} \mathrm{DC} 2 \mathrm{~s}$ in promoting $\mathrm{cDC} 1-$ mediated eosinophil recruitment, but also may provide a longsought explanation for the correlation of exhaled $\mathrm{NO}$ and eosinophilic airway inflammation in asthmatic humans ${ }^{53,54}$, and for how NO exacerbates eosinophilic airway inflammation.

Interestingly, we also found CD24 ${ }^{+} \mathrm{CDC} 2 \mathrm{~s}$, another subset of $\mathrm{CD}_{11} \mathrm{~b}^{+} \mathrm{DCs}$, could negatively regulate eosinophil recruitment during the late eosinophil infiltration phase after challenge by expressing TGF- $\beta 1$ (Fig. 5). We found that it was CD24 cDC2s, but not other DC subsets or AM, that significantly upregulated TGF- $\beta 1$ expression on day 2.5 after the first OVA challenge (Fig. 5c). Mice specifically lacking CD11 $\mathrm{c}^{+}$DCderived TGF- $\beta 1$ displayed no influence on eosinophil recruitment at the early eosinophil infiltration phase after challenge, but had severely augmented eosinophil recruitment at late eosinophil infiltration phase (Fig. 5a, b). By air-pouch assay, we found that $\mathrm{CD} 24^{+}{ }_{\mathrm{CDC}} \mathrm{s}$ inhibited the $\mathrm{CDC} 1$-mediated eosinophil infiltration. Further, we demonstrated that this suppressive effect could be rescued by anti-TGF- $\beta 1$ antibody treatment (Fig. 5f). To further confirm this, $\mathrm{CD} 24^{+} \mathrm{cDC} 2 \mathrm{~s}$ from $T G F-\beta 1^{\mathrm{fl} / \mathrm{fl}} C D 11 c^{\text {cre }}$ mice were injected together with $\mathrm{cDC} 1 \mathrm{~s}$ into the air pouches. The data showed that the $\mathrm{CD} 24^{+} \mathrm{cDC} 2$ loss of TGF- $\beta 1$ could not suppress the eosinophil infiltration anymore (Fig. $5 \mathrm{~g}$ ). These data demonstrated that the inhibitory effect of $\mathrm{CD} 24^{+} \mathrm{CDC} 2 \mathrm{~s}$ on $\mathrm{CDC} 1$-mediated eosinophil recruitment was mediated by TGF- $\beta 1$. Thus, our data revealed a previously unrecognized function for lung $\mathrm{CD} 24^{+} \mathrm{cDC} 2 \mathrm{~s}$ as negative regulators to inhibit lung $\mathrm{CDC} 1$-mediated eosinophil recruitment by TGF- $\beta 1$ during the late eosinophil infiltration phase after challenge.

The results of our current study provide several novel insights into how lung DC subsets contribute to the eosinophil initial migration during memory phase after challenge in a chronic allergic asthma animal model. We found that $\mathrm{cDC} 1 \mathrm{~s}$ directly recruit eosinophils by secreting CCL17 and CCL22, which are critical for early eosinophil infiltration. Furthermore, cDC1mediated eosinophil infiltration is dynamically modulated by other lung DC subsets. After allergen challenge, lung $\mathrm{CD} 24^{-} \mathrm{CD} 11 \mathrm{~b}^{+}$DC2s promote eosinophil infiltration by producing NO on day 1.5 , which promoted CCL17 and CCL22 expression by $\mathrm{cDC} 1 \mathrm{~s}$, whereas $\mathrm{CD} 24^{+} \mathrm{cDC} 2 \mathrm{~s}$ inhibit this process by releasing TGF- $\beta 1$ on day 2.5 (Fig. 6). These insights may facilitate the development of eosinophil-targeted therapeutic approaches for human asthma ${ }^{4}$.

\section{Methods}

Mice. CD11c-DTR, Batf3 ${ }^{-1-}$, langerin-DTR, $\mathrm{NOS}_{2}{ }^{-1-}, \mathrm{CD} 11 c^{\mathrm{Cre}}$, and TGF- $\beta 1^{\mathrm{fl} / \mathrm{fl}}$ mice were purchased from Jackson Laboratories. We generated mice lacking TGF$\beta 1$ in CD11c ${ }^{+}$cells $^{55,56}$. In brief, CD11c Cre mice were crossed with $T G F-\beta 1^{\mathrm{fl} / \mathrm{fl}}$ mice to generate $T G F-\beta 1^{\mathrm{fl} / \mathrm{fl}} C D 11 c^{\mathrm{Cre}}$ mice in which $T G F-\beta 1$ gene exon6 was specifically depleted in CD11c $\mathrm{c}^{+}$cells. The littermate TGF- $\beta 1^{\mathrm{fl} / \mathrm{fl}}$ mice were used as a control. Female C57BL/6 (B6; H-2 Kb) mice, 6-8 weeks of age, were purchased from Vitalriver (Beijing, China). Mice were maintained in specific pathogen-free condition, and all studies were approved by the Laboratory Animal Care Committee of Taishan Medical University.

Reagents. Ovalbumin (OVA) grade V and grade VI, papain, and diphtheria toxin (DT) were from Sigma Aldrich. Imject Alum (aluminum hydroxide) was from Pierce, Rockford, IL. Carboxyfluorescein succinimidyl ester (CFSE) was purchased from Invitrogen. The RNA Mini kit for RNA isolation and RT-PCR kit were from Qiagen. Collagenase type IV and ACK buffer were purchased from Gibco Life Technologies. EDTA was from Invitrogen. N-[3 (aminomethyl) benzyl] 
acetamidine $(1400 \mathrm{~W})$ was from Santa Cruz. Percoll and fetal bovine serum (FBS) were purchased from GE Healthcare. RPMI-1640 medium was from Thermo Fisher Scientific. Clodronate liposomes (CLLs) were prepared as previously described ${ }^{57}$. Briefly, $1 \%$ of the dichloromethylene bisphosphonate $\left(\mathrm{Cl}_{2} \mathrm{MBP}\right)$ could be encapsulated in the liposomes, and the final $\left(\mathrm{Cl}_{2} \mathrm{MBP}\right)$-liposome suspension (4 $\mathrm{ml}$ ) contained approximately $20 \mathrm{mg}$ of $\left(\mathrm{Cl}_{2} \mathrm{MBP}\right)$.

Antibodies. The following reagents were purchased from BD: anti-Siglec F (Clone: E50-2440, Cat: 552126 and 562681, dilution 1:200) and biotin-labeled anti-CD103 (Clone: M290, Cat: 557493, dilution 1:400). The following were purchased from BioLegend: anti-CD64 (Clone: X54-5/7.1, Cat: 139306, dilution 1:200), anti-CD24 (Clone: M1/69, Cat: 101816, dilution 1:200), anti-MHCII (Clone: M5/114.15.2, Cat: 107630 and 107635, dilution 1:800 or 1:200), anti-ly6G (Clone: 1A8, Cat: 127624, dilution 1:800), anti-CCR4 (Clone: 2G12, Cat: 131217, dilution 1:200), and Brilliant Violet $650^{\mathrm{TM}}$ Streptavidin (Cat: 405232, dilution 1:1000). The following were purchased from eBioscience: anti-CD3 (Clone: 145-2C11, Cat: 11-0031-85, dilution 1:400), anti-NOS 2 (Clone: CXNFT, Cat: 53-5920-82, dilution 1:100), anti-CD11b (Clone: M1/70, Cat: 47-0112-82 and 12-0112-82, dilution 1:200 or 1:1600), antiCD11c (Clone: N418, Cat: 45-0114-82, dilution 1:200), anti-F4/80 (Clone: BM8, Cat: 17-4801-82 and 12-4801-82, dilution 1:200), anti-CD4 (Clone: GK1.5, Cat: 170041-82, dilution 1:1600), anti-CD45 (Clone: 30-F11, Cat: 47-0451-82, dilution 1:200), anti-CD90.2 (Clone: 53-2.1, Cat: 48-0902-82, dilution 1:400), Ly6C (Clone: HK1.4, Cat: 48-5932-82 and 25-5932-82, dilution 1:800), anti-mouse CD16/CD32 (Clone: 2.4G2, Cat: 14-0161-86, dilution 1:200), anti-CD25 (Clone: PC61.5, Cat: 102038, dilution 1:200), anti-ST2 (Clone: RMST2-2, Cat: 17-9335-82, dilution 1:100), biotin-labeled anti-CD19 (Clone: MB19-1, Cat: 13-0191-85, dilution 1:800), anti-CD11b (Clone: M1/70, Cat: 13-0112-85, dilution 1:800), anti-NK1.1 (Clone: PK136, Cat: 13-5941-82, dilution 1:800), anti-ter119 (Clone: TER-119, Cat: 135921-85, dilution 1:800), anti-B220 (Clone: RA3-6B2, Cat: 13-0452-85, dilution 1:6400). Streptavidin microbeads (Cat: 130-048-101) were purchased from Miltenyi Biotec. Purified neutralizing antibodies to CCL17/TARC (Cat: AF529) and CCL22/ MDC (Cat: AF439), were obtained from R\&D Systems. Purified blocking antibody against CD4 (Clone GK1.5) was from BioXcell. TGF- $\beta 1$ neutralizing antibody (Cat: MAB240) was from R\&D Systems.

Construction of bone marrow chimeras. For $\mathrm{NOS}_{2}{ }^{-1-}$ and $\mathrm{C} 57 \mathrm{BL} / 6$ chimera mice preparation, $\mathrm{C} 57 \mathrm{BL} / 6$ or $\mathrm{NOS}_{2}{ }^{-1-}$ hosts were firstly irradiated with an X-ray animal irradiator (Rad Source RS2000) with 2 doses of $5.5 \mathrm{~Gy}$ (3-4 h apart). Then, $2 \times 10^{6}$ bone marrow cells from $\mathrm{NOS}_{2}{ }^{-1-}$ or C57BL/6 mice were i.v. transferred into these lethally irradiated C57BL/6 or $\mathrm{NOS}_{2}{ }^{-1-}$ mice. $0.5 \mathrm{mg}$ per $\mathrm{ml}$ neomycin (Sigma-Aldrich) was provided for the first 3 days after irradiation. Mice were employed in the study 8 weeks later.

Depletion of lineage-specific cells in vivo. For depletion of lung $\mathrm{CD} 11 \mathrm{c}^{+}$cells in vivo, CD11c-DTR Tg mice or C57BL/6 mice received an i.t. injection of diphtheria toxin (100 ng per mouse) 1.5 days before the first OVA challenge. For depletion of lung $\mathrm{CDC1s}$, langerin-DTR mice received an intraperitoneal injection of diphtheria toxin (1 mg per mouse) 1 day before the first OVA or papain challenge. In the AM depletion experiments, clodronate (dichloromethylene bisphosphonate, Cl2MBP) or PBS encapsulated liposomes (Encapsula Nanosciences) were injected intratracheally (60 $\mu \mathrm{l}, 1: 2$ dilution in PBS) to $\mathrm{C} 57 \mathrm{Bl} / 6$ mice recipient 1 day before the first OVA challenge. In the NO inhibitor experiments, 1 day prior to the first challenge, mice received $400 \mu \mathrm{g} 1400 \mathrm{~W}$ by i.p. injection and daily twice more from day -1 to day 1 . Control mice received the same volume of saline.

Kinetic model of allergic airway inflammation. Mice were sensitized by i.p. injection of $20 \mu \mathrm{g}$ OVA (Grade VI) emulsified in $2.25 \mathrm{mg}$ of Imject Alum in a total volume of $100 \mu \mathrm{l}$, on days -28 and -14 , and then challenged $(20 \mathrm{~min})$ via the airways with OVA (Grade V; $1 \%$ in saline) on day 0 , day 1 , and day 2 with ultrasonic nebulization (PARIBOY SX, Germany), were culled 0.5 days $(12 \mathrm{~h})$, 1.5 days ( $36 \mathrm{~h}), 2.5$ days $(60 \mathrm{~h}), 4.5$ days $(108 \mathrm{~h}), 6.5$ days ( $156 \mathrm{~h}), 8.5$ days $(204 \mathrm{~h})$ after the first OVA challenge, and bronchoalveolar lavage fluid (Balf) and lungs were collected for analysis. Mice were culled 1.5 days $(36 \mathrm{~h})$ after the first OVA challenge in most of the OVA-induced allergic airway inflammation model, except in indicated experiments in Fig. 1e (middle and right), Fig. 5a, and Fig. $5 \mathrm{c}-\mathrm{h}$, in which mice were culled 2.5 days $(60 \mathrm{~h})$ after the first OVA challenge. Sensitized mice challenged with saline were used as controls.

Papain-induced allergic airway inflammation. Mice were sensitized with $30 \mu \mathrm{g}$ papain each time at intervals days $-28,-27$, and -14 , then i.n. challenged with 10 $\mu \mathrm{g}$ papain on day 0 , and analyzed on day 1 . See ref. ${ }^{58}$ upon which this was based, with some modifications. Sensitized mice challenged with saline were used as controls.

Balf. For Balf, the trachea was cannulated and the lungs were lavaged 2 times with $0.5 \mathrm{ml}$ PBS. Eosinophils in the Balf were analyzed by FACS.
Preparation of lung single cell suspensions. Mice were then killed, and lung parenchyma was collected and digested with $1 \mathrm{mg}$ per $\mathrm{ml}$ collagenase IV for $1 \mathrm{~h}$ at $37^{\circ} \mathrm{C}$. Tissues were filtered through a $70 \mu \mathrm{m}$ cell strainer, and resuspended in $30 \%$ Percoll for centrifugation at $1200 \mathrm{~g}$ for $20 \mathrm{~min}$ at room temperature, followed by incubation with ACK buffer to lyse erythrocytes. All isolated cells were suspended in PBS supplemented with $2 \mathrm{mM}$ EDTA and $1 \%$ FBS. In some indicated experiments, lung single cells were prepared without Percoll treatment for sorting $\mathrm{CD} 45^{+}$ or $\mathrm{CD} 45^{-}$cells.

Flow cytometry and sorting. Lung, Balf, and bone marrow (BM) cells were first blocked with $2.4 \mathrm{G} 2$ to eliminate of Fc receptor-mediated antibody binding. Cells were then incubated for $20 \mathrm{~min}$ on ice with antibodies. Cells were examined by flow cytometry using the Fortessa or Aria II Flow Cytometer (BD Bioscience) and analyzed with FlowJo software 10.0 (Tree Star). Cell sorting was performed on the Aria II Flow Cytometer (BD Bioscience).

The cells were sequentially gated using the following makers: $\mathrm{cDC1s}\left(\mathrm{CD} 64^{-} \mathrm{F} 4 /\right.$ ${ }^{80}{ }^{-}$SiglecF $\left.{ }^{-} \mathrm{CD} 11 \mathrm{c}^{+} \mathrm{IA} / \mathrm{IE}^{+} \mathrm{CD} 103^{+} \mathrm{CD}^{-} 1 \mathrm{~b}^{-}\right), \mathrm{CD}^{2} 4^{+}$cDC2s $\left(\mathrm{CD} 64^{-} \mathrm{F} 4 / 80\right.$ ${ }^{-}$SiglecF $\left.{ }^{-} \mathrm{CD} 11 \mathrm{c}^{+} \mathrm{IA} / \mathrm{IE}^{+} \mathrm{CD} 103^{-} \mathrm{CD}^{-} 1 \mathrm{~b}^{+} \mathrm{CD} 24^{+}\right), \mathrm{CD}^{-} 4^{-} \mathrm{CD}_{11 b^{+}} \mathrm{DC} 2 \mathrm{~s}(\mathrm{CD} 64$ ${ }^{-} \mathrm{F} 4 / 80^{-}{ }^{-}$SiglecF $\left.{ }^{-} \mathrm{CD} 11 \mathrm{c}^{+} \mathrm{IA} / \mathrm{IE}^{+} \mathrm{CD} 103^{-}{ }^{-} \mathrm{CD} 11 \mathrm{~b}^{+} \mathrm{CD} 24^{-}\right)$, MCs $\left(\mathrm{CD} 64^{+} \mathrm{F} 4 / 80\right.$

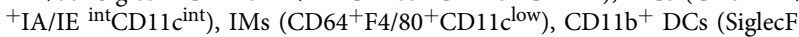
$\left.{ }^{-} \mathrm{CD} 11 \mathrm{c}^{+} \mathrm{IA} / \mathrm{IE}^{+} \mathrm{CD} 103^{-} \mathrm{CD} 11 \mathrm{~b}^{+}\right)$. In some indicated experiments, $\mathrm{cDC} 1 \mathrm{~s}$ were sequentially gated using the following makers $\left(\right.$ SiglecF $^{-} \mathrm{CD} 11 \mathrm{c}^{+} \mathrm{IA} / \mathrm{IE}^{+} \mathrm{CD} 103$ $\left.{ }^{+} \mathrm{CD} 11 \mathrm{~b}^{-}\right)$

Enzyme-linked immunosorbent assay. Cytokine and chemokine concentrations in cell-free Balf were measured with Multiplex reagents (Millipore). CCL17/TARC and CCL22/MDC in the Balf were analyzed using ELISAs (R\&D Systems, Minneapolis, MN) specific for mouse CCL17/TARC (Catalog Number: MCC170) and mouse CCL22/MDC (Catalog Number: MCC220) according to the manufacturer's protocols.

Griess assay. Nitrite production was assayed by measurement of the nitrite ion concentration with the Griess assay (Beyotime Institute of Biotechnology, Shanghai, China) according to the manufacturer's protocol. Lung CD45 ${ }^{+}$cells $\left(1 \times 10^{6}\right.$ cells), cDC1s, CD24- ${ }^{-} \mathrm{CD} 11 \mathrm{~b}^{+} \mathrm{DC} 2 \mathrm{~s}, \mathrm{CD} 24^{+} \mathrm{cDC} 2 \mathrm{~s}$, MCs, AMs and IMs $\left(5 \times 10^{4}\right.$ cells) were sorted from mice 1.5 days after the first OVA challenge and cultured for $48 \mathrm{~h}$. NO production was measured in the supernatants of the cultured cells.

Q-PCR. For quantitative PCR analysis, total RNA from sorted cells was extracted using RNeasy Mini Kit (Qiagen). cDNA was synthesized according to the manufacturers' instructions through a QuantiTect Reverse Transcription Kit (Qiagen). QPCR was performed with the SYBR Green Master Mix (Qiagen) using the Rotor-Gene Q (Qiagen) or LightCycler480 (Roche) according to the manufacturer's protocol. Target gene expression was calculated using the comparative method for relative quantification after normalization to GAPDH gene expression. The sequences for primers were as follows: CCL5 (5'-GCTGCTTTGCCTACCTCTCC-3' reverse, 5'TCGAGTGACAAACACGACTGC-3'); CCL8 (forward, 5'-TCTACGCA

GTGCTTCTTTGCC-3'; reverse, 5'-AAGGGGGATCTTCAGCTTTAGTA-3'); CCL11 (forward, 5'-GAATCACCAACAACAGATGCAC-3'; reverse, 5'-ATCCTGG ACCCACTTCTTCTT-3'); CCL17 (forward, 5'-TACCATGAGGTCACTTCAGATGC3'; reverse, 5'-GCACTCTCGGCCTACATTGG-3'); CCL22 (forward, 5'-AGGTCCCT ATGGTGCCAATGT-3'; reverse, 5'-CGGCAGGATTTTGAGGTCCA-3'); CCL24 (forward, 5'-ATTCTGTGACCATCCCCTCAT-3'; reverse, 5'-TGTATGTGCCTCTG AACCCAC-3'); $\mathrm{NOS}_{2}$ (forward, 5'-TCAACATCTCCTGGTGGAAC-3'; reverse, 5'-A GCACACATGCAGAATGAGTA-3'); TGF- $\beta 1$ (forward, $5^{\prime}$-ACCATGCCAACTTCT GTCTG-3'; reverse, 5'-CGGGTTGTGTTGGTTGTAGA-3'); and GAPDH (forward, 5'-TGTGTCCGTCGTGGATCTGA-3'; reverse, 5'-TTGCTGTTGAAGTCGCAGG $\left.A G-3^{\prime}\right)$.

Air-pouch assay. The subcutaneous air-pouch model of DC-induced eosinophilic inflammation was used ${ }^{36,37}$. Subcutaneous air pouches were generated by injection of $3 \mathrm{ml}$ of air into the subcutaneous tissue on the back of anesthetized female mice. Air pouches were reinflated 3 days later. The next day, $\mathrm{CD} 45^{-}$cells or $\mathrm{CD}^{+} 5^{+}$cells, lung $\mathrm{CD}_{4}^{+} \mathrm{T}$ cells, $\mathrm{CD} 45^{+}$lin $^{-} \mathrm{CD} 90.2^{+} \mathrm{CD} 127^{+} \mathrm{CD} 25^{+} \mathrm{ST} 2{ }^{+} \mathrm{ILC} 2$ s, or DC subsets $\left(1-5 \times 10^{4}\right.$ cells $)$, were injected into the pouches; $12 \mathrm{~h}$ later, pouches were washed with $3 \mathrm{ml}$ cold PBS. CD11 $\mathrm{b}^{+} \mathrm{IA} / \mathrm{IE}^{-}$SiglecFhiSSChi eosinophil counts were obtained with FACS analysis. For some experiments, lung $\mathrm{CD} 45^{-}$cells or $\mathrm{CD} 45^{+}$ cells (left, $1 \times 10^{6}$ ) were sorted from mice 1.5 days after the first OVA challenge; lung $\mathrm{CD} 4^{+} \mathrm{T}$ cells $\left(\right.$ middle, $1 \times 10^{5}$ ) or ILC2s (right, $1 \times 10^{4}$ ) were sorted from mice 1.5 days and 2.5 days after the first OVA challenge. In certain recruitment assays, lung DC subsets were mixed with $2.5 \mu \mathrm{g}$ per ml anti-CCL17/TARC (Fig. 3e), $1.5 \mu \mathrm{g}$ per $\mathrm{ml}$ anti-CCL22/MDC, or $10 \mu \mathrm{g}$ per ml anti-TGF- $\beta 1$ blocking antibody in the air pouches. In certain experiments, CCL17 $(150 \mathrm{pg}, 500 \mu \mathrm{l})$ or CCL22 $(150 \mathrm{pg}, 500 \mu \mathrm{l})$ in a temperature-sensitive surface gel was injected into the air pouches, and $5 \mathrm{~h}$ later, eosinophils recruited into the air pouches were assessed.

Transwell assay. The direct recruitment of lung eosinophils was assayed using Transwell ${ }^{\mathrm{TM}}$ inserts (pore size $3 \mu \mathrm{m}$ ) and 24-well culture plates (Corning Costar, 
Cambridge, MA). Briefly, bone marrow $\mathrm{Gr} 1^{-} \mathrm{F} 4 / 80^{+} \mathrm{SSC}^{\text {high }}$ eosinophils were sorted from challenged mice with a FACSAria II flow cytometer and then labeled with $0.1 \mu \mathrm{mol}$ CFSE. $2 \times 10^{5}$ CFSE-labeled BM eosinophils in $0.2 \mathrm{ml} \mathrm{RPMI-1640}$ medium containing $10 \%$ FBS were transferred to the upper compartment of the transwell insert. Lung CDC1s, CD24 ${ }^{+} \mathrm{DC} 2 \mathrm{~s}$, or MCs $\left(1.5 \times 10^{4}\right)$ were sorted (FACSAria II) from challenged C57BL/6 mice 1.5 days after the first OVA challenge and were added in the lower compartment of the transwell insert. RPMI-1640 containing $10 \%$ FBS was used as a control. After $12 \mathrm{~h}$ incubation at $37^{\circ} \mathrm{C}$ in an atmosphere with $5 \% \mathrm{CO}_{2}$, the number of $\mathrm{CFSE}^{+}$eosinophils that had migrated from the upper to the lower compartment was counted using FACS. In certain experiments, CCL17 (100 pg per ml) or CCL22 (100 pg per ml) were added in the lower compartment of the transwell insert. $2 \times 10^{5}$ CFSE-labeled bone marrow eosinophils were transferred to the upper compartment of the transwell insert. After $2 \mathrm{~h}$ incubation at $37^{\circ} \mathrm{C}$ and $5 \% \mathrm{CO}_{2}$, the number of $\mathrm{CFSE}^{+}$eosinophils that had migrated from the upper to the lower compartment was counted using FACS.

Adoptive transfer. To test the capacities of lung cDC1s, CD24+ DC2s, or MCs from challenged mice to induce eosinophil infiltration, we performed an adoptive transfer experiment. Lung cDC1s, CD24 ${ }^{+} \mathrm{DC} 2 \mathrm{~s}$, or MCs $\left(5 \times 10^{4}\right.$ cells, $50 \mu \mathrm{l}, n=$ 3-4 mice per group) were sorted from mice 1.5 days after the first OVA challenge using BD FACSAria II Flow Cytometer and were administered i.t. into sensitized C57B/6 mice on day 0 . Mice were culled $48 \mathrm{~h}$ after adoptive transfer for analysis of lung eosinophil infiltration.

Statistics. For all relevant animal experiments, age-matched female mice were randomly chosen to be in different treatment groups. Each group was typically composed of three to nine (except for the $\mathrm{NOS}_{2}{ }^{-1-}$ chimeric mice experiment, which was composed of 6-14) mice 8-12 weeks of age, and two to three independent experiments were performed for every assay. Statistical analysis was performed in GraphPad Prism software 6.0. Data were analyzed by application of twotailed unpaired Student's $t$ test where necessary. A $P$ value of less than 0.05 was considered significant.

\section{Data availability}

The data that support this study are available within the article and its Supplementary Information files or available from the authors upon reasonable request.

Received: 4 October 2017 Accepted: 30 August 2018

Published online: 24 September 2018

\section{References}

1. Lambrecht, B. N. \& Hammad, H. The immunology of asthma. Nat. Immunol. 16, 45-56 (2015)

2. Rothenberg, M. E. Humanized anti-IL-5 antibody therapy. Cell 165, 509 (2016).

3. Rothenberg, M. E. \& Hogan, S. P. The eosinophil. Annu. Rev. Immunol. 24, 147-174 (2006).

4. Fulkerson, P. C. \& Rothenberg, M. E. Targeting eosinophils in allergy, inflammation and beyond. Nat. Rev. Drug Discov. 12, 117-129 (2013).

5. Lambrecht, B. N., Persson, E. K. \& Hammad, H. Myeloid cells in asthma. Microbiol. Spectr. 5, doi: 0.1128/microbiolspec.MCHD-0053-2016 (2017).

6. Travers, J. \& Rothenberg, M. E. Eosinophils in mucosal immune responses. Mucosal Immunol. 8, 464-475 (2015).

7. Lee, J. J. et al. Defining a link with asthma in mice congenitally deficient in eosinophils. Science 305, 1773-1776 (2004).

8. Jacobsen, E. A. et al. Allergic pulmonary inflammation in mice is dependent on eosinophil-induced recruitment of effector T cells. J. Exp. Med. 205, 699-710 (2008).

9. de Groot, J. C., Ten Brinke, A. \& Bel, E. H. Management of the patient with eosinophilic asthma: a new era begins. ERJ Open Res. 1, 00024 (2015).

10. Landolina, N. A. \& Levi-Schaffer, F. Eosinophils as a pharmacological target for the treatment of allergic diseases. Curr. Opin. Pharmacol. 17, 71-80 (2014).

11. Nakayama, T. et al. Th2 cells in health and disease. Annu. Rev. Immunol. 35, 53-84 (2017)

12. Blanchard, C. \& Rothenberg, M. E. Biology of the eosinophil. Adv. Immunol. 101, 81-121 (2009).

13. Bernink, J. H., Germar, K. \& Spits, H. The role of ILC2 in pathology of type 2 inflammatory diseases. Curr. Opin. Immunol. 31, 115-120 (2014).

14. Motomura, Y. et al. Basophil-derived interleukin- 4 controls the function of natural helper cells, a member of ILC2s, in lung inflammation. Immunity 40, 758-771 (2014).

15. Martinez-Gonzalez, I., Steer, C. A. \& Takei, F. Lung ILC2s link innate and adaptive responses in allergic inflammation. Trends Immunol. 36, 189-195 (2015).

16. Endo, Y. et al. The interleukin-33-p38 kinase axis confers memory $\mathrm{T}$ helper 2 cell pathogenicity in the airway. Immunity 42, 294-308 (2015).
17. Lambrecht, B. N. \& Hammad, H. Lung dendritic cells in respiratory viral infection and asthma: from protection to immunopathology. Annu. Rev. Immunol. 30, 243-270 (2012)

18. Durai, V. \& Murphy, K. M. Functions of murine dendritic cells. Immunity 45, 719-736 (2016).

19. Pulendran, B., Tang, H. \& Denning, T. L. Division of labor, plasticity, and crosstalk between dendritic cell subsets. Curr. Opin. Immunol. 20, 61-67 (2008).

20. Kopf, M., Schneider, C. \& Nobs, S. P. The development and function of lungresident macrophages and dendritic cells. Nat. Immunol. 16, 36-44 (2014).

21. Furuhashi, K. et al. Mouse lung CD103+ and CD11b high dendritic cells preferentially induce distinct CD4+ T-cell responses. Am. J. Respir. Cell Mol. Biol. 46, 165-172 (2012).

22. Everts, B. et al. Migratory CD103+ dendritic cells suppress helminth-driven type 2 immunity through constitutive expression of IL-12. J. Exp. Med. 213 35-51 (2016)

23. Nakano, H. et al. Pulmonary CD103(+) dendritic cells prime Th2 responses to inhaled allergens. Mucosal Immunol. 5, 53-65 (2012).

24. Ortiz-Stern, A. et al. Langerin + dendritic cells are responsible for LPSinduced reactivation of allergen-specific Th2 responses in postasthmatic mice. Mucosal Immunol. 4, 343-353 (2011).

25. Plantinga, $\mathrm{M}$. et al. Conventional and monocyte-derived $\mathrm{CD} 11 \mathrm{~b}(+)$ dendritic cells initiate and maintain $\mathrm{T}$ helper 2 cell-mediated immunity to house dust mite allergen. Immunity 38, 322-335 (2013).

26. Zhou, Q. et al. GM-CSF-licensed CD11b+lung dendritic cells orchestrate Th2 immunity to Blomia tropicalis. J. Immunol. 193, 496-509 (2014).

27. Tussiwand, R. et al. Klf4 expression in conventional dendritic cells is required for T helper 2 cell responses. Immunity 42, 916-928 (2015).

28. Raymond, M. et al. Selective control of SIRP-alpha-positive airway dendritic cell trafficking through $\mathrm{CD} 47$ is critical for the development of $\mathrm{T}(\mathrm{H}) 2$ mediated allergic inflammation. J. Allergy Clin. Immunol. 124, 1333-1342 (2009).

29. Medoff, B. D. et al. CD11b + myeloid cells are the key mediators of Th2 cell homing into the airway in allergic inflammation. J. Immunol. 182, 623-635 (2009).

30. Williams, J. W. et al. Transcription factor IRF4 drives dendritic cells to promote Th2 differentiation. Nat. Commun. 4, 2990 (2013).

31. Lambrecht, B. N., Salomon, B., Klatzmann, D. \& Pauwels, R. A. Dendritic cells are required for the development of chronic eosinophilic airway inflammation in response to inhaled antigen in sensitized mice. J. Immunol. 160, 4090-4097 (1998).

32. van Rijt, L. S. et al. In vivo depletion of lung $\mathrm{CD} 11 \mathrm{c}+$ dendritic cells during allergen challenge abrogates the characteristic features of asthma. J. Exp. Med. 201, 981-991 (2005).

33. Guo, L. et al. Innate immunological function of TH2 cells in vivo. Nat. Immunol. 16, 1051-1059 (2015).

34. Abdala Valencia, H., Loffredo, L. F., Misharin, A. V. \& Berdnikovs, S. Phenotypic plasticity and targeting of Siglec-F(high) CD11c(low) eosinophils to the airway in a murine model of asthma. Allergy 71, 267-271 (2016).

35. Walsh, E. R. et al. Strain-specific requirement for eosinophils in the recruitment of $\mathrm{T}$ cells to the lung during the development of allergic asthma. J. Exp. Med. 205, 1285-1292 (2008).

36. Colvin, R. A. et al. Synaptotagmin-mediated vesicle fusion regulates cell migration. Nat. Immunol. 11, 495-502 (2010).

37. He, H. et al. NK cells promote neutrophil recruitment in the brain during sepsis-induced neuroinflammation. Sci. Rep. 6, 27711 (2016).

38. Sung, S. S. et al. A major lung CD103 (alphaE)-beta7 integrin-positive epithelial dendritic cell population expressing Langerin and tight junction proteins. J. Immunol. 176, 2161-2172 (2006).

39. Jahnsen, F. L. et al. Accelerated antigen sampling and transport by airway mucosal dendritic cells following inhalation of a bacterial stimulus. J. Immunol. 177, 5861-5867 (2006).

40. Rigaux, P., Killoran, K. E., Qiu, Z. \& Rosenberg, H. F. Depletion of alveolar macrophages prolongs survival in response to acute pneumovirus infection. Virology 422, 338-345 (2012).

41. Hildner, K. et al. Batf3 deficiency reveals a critical role for CD8alpha+ dendritic cells in cytotoxic T cell immunity. Science 322, 1097-1100 (2008).

42. Guilliams, M. et al. Unsupervised high-dimensional analysis aligns dendritic cells across tissues and species. Immunity 45, 669-684 (2016).

43. Bajana, S., Turner, S., Paul, J., Ainsua-Enrich, E. \& Kovats, S. IRF4 and IRF8 act in $\mathrm{CD} 11 \mathrm{c}+$ cells to regulate terminal differentiation of lung tissue dendritic cells. J. Immunol. 196, 1666-1677 (2016).

44. Yoshie, O. \& Matsushima, K. CCR4 and its ligands: from bench to bedside. Int. Immunol. 27, 11-20 (2015).

45. Sokol, C. L. \& Luster, A. D. The chemokine system in innate immunity. Cold Spring Harb. Perspect. Biol. 7, a016303 (2015). 
46. Liu, L. Y., Jarjour, N. N., Busse, W. W. \& Kelly, E. A. Chemokine receptor expression on human eosinophils from peripheral blood and bronchoalveolar lavage fluid after segmental antigen challenge. J. Allergy Clin. Immunol. 112, 556-562 (2003)

47. Zlotnik, A. \& Yoshie, O. The chemokine superfamily revisited. Immunity 36, 705-716 (2012).

48. Xiong, Y., Karupiah, G., Hogan, S. P., Foster, P. S. \& Ramsay, A. J. Inhibition of allergic airway inflammation in mice lacking nitric oxide synthase 2. J. Immunol. 162, 445-452 (1999).

49. Trifilieff, A. et al. Inducible nitric oxide synthase inhibitors suppress airway inflammation in mice through down-regulation of chemokine expression. $J$. Immunol. 165, 1526-1533 (2000).

50. Possa, S. S., Leick, E. A., Prado, C. M., Martins, M. A. \& Tiberio, I. F. Eosinophilic inflammation in allergic asthma. Front. Pharmacol. 4, 46 (2013).

51. Gold, M. J. et al. Group 2 innate lymphoid cells facilitate sensitization to local, but not systemic, TH2-inducing allergen exposures. J. Allergy Clin. Immunol. 133, 1142-1148 (2014)

52. Crapster-Pregont, M., Yeo, J., Sanchez, R. L. \& Kuperman, D. A. Dendritic cells and alveolar macrophages mediate IL-13-induced airway inflammation and chemokine production. J. Allergy Clin. Immunol. 129, 1621-1627 (2012).

53. Ritz, T. \& Trueba, A. F. Airway nitric oxide and psychological processes in asthma and health: a review. Ann. Allergy Asthma Immunol. 112, 302-308 (2014).

54. Barnes, P. J. et al. Exhaled nitric oxide in pulmonary diseases: a comprehensive review. Chest 138, 682-692 (2010).

55. Denney, L. et al. Pulmonary epithelial cell-derived cytokine TGF-betal is a critical cofactor for enhanced innate lymphoid cell function. Immunity 43, 945-958 (2015).

56. Gao, Y. et al. Control of T helper 2 responses by transcription factor IRF4dependent dendritic cells. Immunity 39, 722-732 (2013).

57. $\mathrm{Xu}, \mathrm{Y}$. et al. Macrophages transfer antigens to dendritic cells by releasing exosomes containing dead-cell-associated antigens partially through a ceramide-dependent pathway to enhance CD4(+) T-cell responses. Immunology 149, 157-171 (2016).

58. Halim, T. Y. et al. Group 2 innate lymphoid cells license dendritic cells to potentiate memory TH2 cell responses. Nat. Immunol. 17, 57-64 (2016)

\section{Acknowledgements}

We gratefully acknowledge Dr. Bali Pulendran for advice and helpful discussions. We thank the staff of the Experimental Animal Laboratory of Taishan Medical University, especially Qiuling Zhang for assistance with the maintenance of mice. This work was supported by grants from the National Basic Research Program of China (2015CB943203), the National Natural Science Foundation of

China (NSFC81401328, NSFC81272315, NSFC81172882, NSFC31500715), and the Natural Science Foundation of Shandong Province (ZR2013HL064, ZR2011CM037, ZR2015HQ021).

\section{Author contributions}

Experiments were designed by S.Y. and H.T.; S.Y. performed most of the experiments (with help from R.N. and G.Z. for some) and designed the figures; J.Z. performed a lot of research work for the revision of the manuscript. R.N. and G.Z. performed the Q-PCR and "air-pouch" recruitment assay in vivo; J.L., H.H., Y.W., and X.J. prepared single cell suspensions from lung, and performed phenotypic analysis; L.K. and M.W. performed cell sorting of lung; W.S. and Y.S. assisted with data analyses. The manuscript was written by S.Y. and H.T.

\section{Additional information}

Supplementary Information accompanies this paper at https://doi.org/10.1038/s41467018-06316-9.

Competing interests: The authors declare no competing interests.

Reprints and permission information is available online at http://npg.nature.com/ reprintsandpermissions/

Publisher's note: Springer Nature remains neutral with regard to jurisdictional claims in published maps and institutional affiliations.

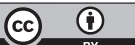

Open Access This article is licensed under a Creative Commons Attribution 4.0 International License, which permits use, sharing, adaptation, distribution and reproduction in any medium or format, as long as you give appropriate credit to the original author(s) and the source, provide a link to the Creative Commons license, and indicate if changes were made. The images or other third party material in this article are included in the article's Creative Commons license, unless indicated otherwise in a credit line to the material. If material is not included in the article's Creative Commons license and your intended use is not permitted by statutory regulation or exceeds the permitted use, you will need to obtain permission directly from the copyright holder. To view a copy of this license, visit http://creativecommons.org/ licenses/by/4.0/.

(C) The Author(s) 2018 